\title{
Evaluation of the Wind Power in the State of Paraíba Using the Mesoscale Atmospheric Model Brazilian Developments on the Regional Atmospheric Modelling System
}

\author{
Francisco José Lopes de Lima, ${ }^{1}$ Enilson Palmeira Cavalcanti, ${ }^{1}$ \\ Enio Pereira de Souza, ${ }^{1}$ and Emerson Mariano da Silva ${ }^{2}$ \\ ${ }^{1}$ Departamento de Ciências Atmosféricas (DCA), Universidade Federal de Campina Grande (UFCG), \\ 882 Aprígio Veloso Avenue, Bodocongó, Campina Grande, PB, Brazil \\ ${ }^{2}$ Departamento de Física (DF), Universidade Estadual do Ceará (UECE), 1700 Paranjana Avenue, \\ Itaperi, Fortaleza, CE, Brazil
}

Correspondence should be addressed to Francisco José Lopes de Lima, francisco.lopes.lima@gmail.com

Received 2 April 2012; Accepted 9 July 2012

Academic Editors: C. J. Koroneos and S. Senthilarasu

Copyright (C) 2012 Francisco José Lopes de Lima et al. This is an open access article distributed under the Creative Commons Attribution License, which permits unrestricted use, distribution, and reproduction in any medium, provided the original work is properly cited.

\begin{abstract}
This work aims to describe the wind power density in five sites in the State of Paraiba, as well as to access the ability of the mesoscale atmospheric model Brazilian developments on the regional atmospheric modeling system (BRAMS) in describing the intensity of wind in São Gonçalo Monteiro, Patos, Campina Grande, and João Pessoa. Observational data are wind speed and direction at $10 \mathrm{~m}$ high, provided by the National Institute of Meteorology (INMET). We used the numerical model BRAMS in simulations for two different months. We ran the model for rainy months: March and April. It was concluded that the BRAMS model is able to satisfactorily reproduce the monthly cycle of the wind regime considered, as well as the main direction. However the model tends to underestimate the wind speed.
\end{abstract}

\section{Introduction}

As the using of wind power in the world grows, new technologies of generators and topology for wind power plants have been created in order to improve the utilization of energy from wind and its transmission. Numerical models of weather forecast are largely used in varied meteorological centers and find a range of applications in agriculture, water resources, tourism, and so forth. Forced by data and global models, it is common to local meteorological centers keeping systems of numerical forecast based on atmospheric models of limited area, with spatial resolutions of kilometers, typically.

Some researches related to wind behavior are concentrated on the problem of adjustment of statistics distribution to data of wind speed $([1,2]$ and others). Results of these researches also indicate the distribution of Weibull as the one that fits better to these data.
According to Sauer et al. [3], Brazil offers excellent sites to install wind parks, and the best area is found along its coast. However, he indicates that in the countryside, particularly in northeast, where is located the State of Paraíba, there are found sites with capacity of wind power generation.

Various numerical models of mesoscale such as (regional atmospheric modeling system) RAMS described in Cotton et al. [4], (regional spectral model) RSM described in Juang and Kanamitsu [5], and MM5 described in Duhdia et al. [6] solved physical processes from the surface to high atmosphere. These models are applied from the weather forecast to the measurement of pollutants dispersion.

Among these, the (brazilian developments on the regional atmospheric modeling system) BRAMS model, developed from RAMS, whose basic structure is described by Pielke et al. [7]; Walko et al. [8]; and Cotton et al. [4]. However, an objective and brief description of this model can be found in Cavalcanti [9]. 
TABLE 1: Relation between the stations of surface from INMET and clockwise data of wind direction and speed to the State do Paraíba.

\begin{tabular}{lcccc}
\hline Site & Number synoptic & Latitude $(\mathrm{S})$ & Longitude $(\mathrm{W})$ & \\
\hline São Gonçalo & 82698 & $6^{\circ} 50^{\prime}$ & $38^{\circ} 19^{\prime}$ & Height $(\mathrm{m})$ \\
Monteiro & 82792 & $7^{\circ} 52^{\prime}$ & $37^{\circ} 07^{\prime}$ & 235 \\
Patos & 82791 & $7^{\circ} 01^{\prime}$ & $37^{\circ} 17^{\prime}$ & 596 \\
Campina Grande & 82795 & $7^{\circ} 13^{\prime}$ & $35^{\circ} 53^{\prime}$ & 250 \\
João Pessoa & 82798 & $7^{\circ} 07^{\prime}$ & $34^{\circ} 53^{\prime}$ & 508 \\
\hline
\end{tabular}

This model has a complete and sophisticated set of physical parameterization to simulate the leading processes of the evolution of the atmospherical state. It contains in its code various options of physical parameterizations. Parameterizations: radiation proposed by Chen and Cotton [10], and of deep convection of Kuo type [11, 12], modified by Molinari [13] and Molinari and Corsetti [14], and the one by Grell and Dévényi [15] and other of shallow convection developed and implemented by Souza [16]. Turbulence on planetary limit layer is calculated according to Mellor and Yamada [17], and microphysics follow the scheme described by Walko et al. [8].

In its more recent version the model counts with a parameterization for the photochemical processes on the atmosphere [18], besides the adequate treatment for urban areas by means of scheme (town energy budget) TEB, introduced in its version 4.3 of RAMS model [19].

The general objective of this study is to evaluate the capacity of the numerical model BRAMS to simulate wind fields, aiming at the evaluation of wind power, in the State of Paraíba. Thus, it will be made an evaluation of wind power in the regions of São Gonçalo, Patos, Monteiro, Campina Grande, and João Pessoa, in State of Paraíba, using data observed and simulated by the regional model BRAMS, to generate primary maps of the wind power of the region.

\section{Material and Methods}

Data used in this research are clockwise observations of wind direction and speed, collected in five stations, located in the State of Paraíba, and they are meteorological stations of surface from Climatological Net of Northeast (RedeClimatológica do Nordeste) managed by the National Institute of Meteorology (Instituto Nacional de Meteorologia (INMET)). Sensors are at 10 meters high. The localization of the stations and its respective latitude, longitude, and height are shown in Table 1.

Numerical simulations were accomplished using the model BRAMS, aiming to evaluate the wind power in the State of Paraíba, in comparison to observational data. It was established two periods: March and April, 1977 and 1981, corresponding to the seasons of the year with less wind intensity, that is, the rainy period.

In wind simulation with the BRAMS aiming at the wind power generation it is necessary to use high resolution. Thus, it was adopted two rails. The main rail that has a rectangular is of 80 points in direction $x$ and 80 points in direction $y$, with a space of $16 \mathrm{~km}$ between each point of the rail, corresponding to an area that covers almost all northeast

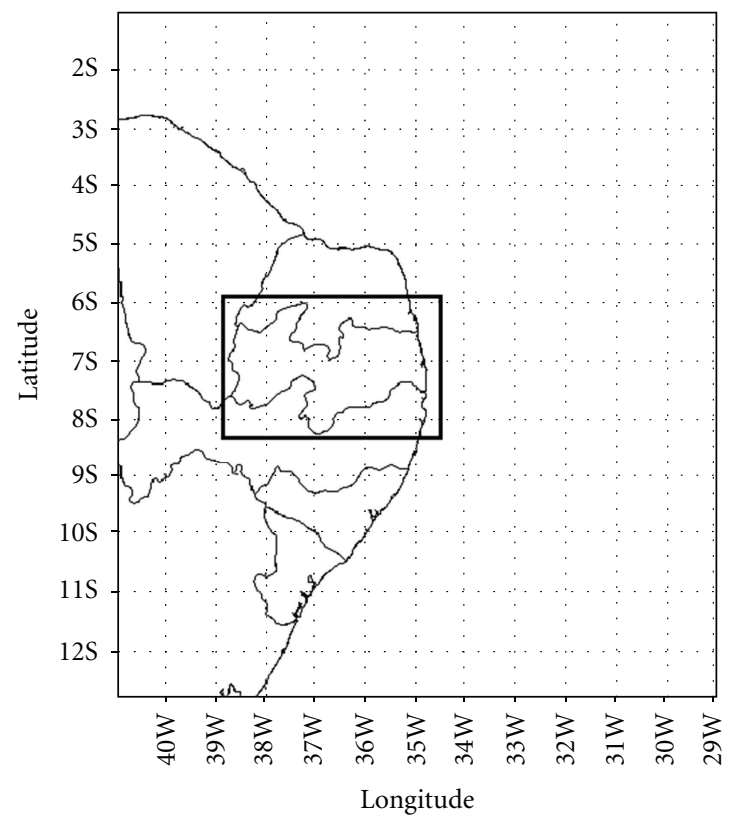

FIGURE 1: Grid used $80 \times 80$ points. Useful area for analysis: colorful area.

region: Ceará, Rio Grande do Norte, Paraíba, Pernambuco, Alagoas, Sergipe, and part of Bahia. And the rail nestled, located between the limits of the small rectangle, in blue, having 122 points in direction $x$ and 66 points in direction $y$, with a space of $4 \mathrm{~km}$ between each one, corresponding to the region of Paraíba. The frequency of the analysis made by the model was standardized to clockwise intervals and with two rails having 9 degrees of soil layers. Figure 1 presents the view of the rails.

All rails present polar stereographic projection and the same vertical structure, which consists of 42 degrees with enlargement reason of 1, 2, and a space of, at most, $1000 \mathrm{~m}$. Lateral Newtonian relaxation is activated using 5 points, reaching $1800 \mathrm{~s}$, or $30 \mathrm{~min}$, as a constant value for all the simulated period. Top Newtonian relaxation has a scale of $21.600 \mathrm{~s}$, or $6 \mathrm{~h}$. The Newtonian relaxation in the interior of the domain reached the same value of the Newtonian relaxation of the top. For the parameterization of the radiation the scheme of Chen type is used. The parameterization of microphysics used is of the level 2 in the model. The parameterization of convection was also activated, being the Kuo type $[11,12,21]$, the one chosen. For the parameterization of turbulent the scheme of Mellor-Yamada was chosen. 
To adjust data obtained by BRAMS (representative of the railed area) with the data observed (punctual) the statistic method was used, according to Reis Junior [22] that is based on the use of the mean and of the standard deviation of the series observed and simulated given as

$$
\phi_{c i}=\left(\phi_{i}-\overline{\phi_{i}}\right) \frac{\sigma_{o}}{\sigma_{i}}+\overline{\phi_{o}},
$$

where $\phi_{i}$ represents a value of the simulation, $\bar{\phi}_{i}$ the mean of the simulated values, $\sigma_{o}$ the mean of the observed series, $\sigma_{i}$ the standard deviation of the simulated series, and, finally, $\bar{\phi}_{o}$ represents the mean of the observational data.

By the studies of Weber et al. [23], Maria [24], and Cunha [25], it is concluded that the best way to evaluate the model is using a set of statistic indexes, aiming to minimize interpretation mistakes. For this reason, in this work a set of 3 statistic indexes is used: mean absolute error, mean-square error and correction index.

Mean absolute-error (EA) is given as

$$
\mathrm{EA}=\frac{1}{N} \sum_{i=1}^{n}\left|\phi_{i}-\phi_{o}\right|
$$

By the definition, EA only can reach positive values; thus, the less is the value, the bigger is the similarity between the series. Mean square error (EQM) is given by the sum of the squares of the differences between the results of the model and the observations:

$$
\mathrm{EQM}=\left[\frac{1}{N} \sum_{i=1}^{N}\left(\phi_{i}-\phi_{o}\right)^{2}\right]^{1 / 2} .
$$

It can reach any positive value and has the same units of measurement of the series. The similarity of the simulated and observed series is bigger as the near of zero is the error measurement. In Table 2 there is a more refined interpretation of the coefficient of correlation by Pearson.

The value of a correlation coefficient is not a guarantee that the variables involved are really correlated although before any conclusions about the values of the correlation coefficients, the application of a statistical test is necessary in order to know the real degree of relation between the variable analyzed. In order to test the equality between two means, Student's $t$-test by is largely used [26, 27]. The test of significance $t$ by Student was applied having the following parameterization values, $t$ :

$$
t=\frac{r \sqrt{N-2}}{\sqrt{1-r^{2}}},
$$

where $N$ is the number of data.

From (4) the critical coefficient of correlation $\left(r_{c}\right)$ was extracted, that is, a value which accepts or not the statistical hypothesis, $r_{c}$, given by

$$
r_{c}=\sqrt{\frac{t^{2}}{(N-2)+t^{2}}} .
$$

In this work the variable used has a series of data of 31 and 30 days, respectively. The critical correlation indexes $r_{c}$ will be calculated.
TABLE 2: Coefficient of statistics correction, or coefficient of correction by Pearson. Source: Devore [20].

\begin{tabular}{lc}
\hline Intervals & Definition \\
\hline 0.00 a 0.19 & Very weak correlation \\
0.20 a 0.39 & Weak correlation \\
0.40 a 0.69 & Moderate correlation \\
0.70 a 0.89 & Strong correlation \\
0.90 a 1.00 & Very strong correlation \\
\hline
\end{tabular}

For the correlation $N=31$, that is, 31 days corresponding to the month of March, $N-2=29$, which are the degrees of freedom. So the values of $t$ and $r_{c}$ are

(a) for $99 \%$ of significance, that is, with an error of $1 \%$ $(\alpha=0.01), t=2.462 ; r_{c}=0.42$

(b) for $95 \%$ of significance, that is, with an error of $5 \%$ $(\alpha=0.05), t=1.699 ; r_{c}=0.30$

(c) for $90 \%$ of significance, that is, with an error of $10 \%$ $(\alpha=0.10), t=1.311 ; r_{c}=0.24$.

For the correlation $N=30$, that is, 30 days corresponding to the month of April, $N-2=28$, which are the degrees of freedom. So the values of $t$ and $r_{c}$ are

(i) for $99 \%$ of significance, that is, with an error of $1 \%$ $(\alpha=0.01), t=2.467 ; r_{c}=0.42$

(ii) for $95 \%$ of significance, that is, with an error of $5 \%$ $(\alpha=0.05), t=1.701 ; r_{c}=0.30$

(iii) for $90 \%$ of significance, that is, with an error of $10 \%$ $(\alpha=0.10), t=1.313 ; r_{c}=0.24$.

It means that, for the correlation coefficients obtained with 29 and 28 degrees of freedom, the statistical significance that shows the correlation between the variables is of $99 \%$, $95 \%$, and $90 \%$, for $r$ equal or superior to $0.42,0.30$, and 0.24 , respectively.

The result obtained can suggest the acceptance of the hypothesis of null coefficient or not. In case of the correlation coefficient calculated is equal or superior to the value of $t$ critical for a determined degree of freedom the percentage of significance, the null hypothesis is rejected, and the trend observed is true for that degree of significance obtained $[27,28]$.

\section{Results of the Simulations}

From Figures 2 to 6 the time series of wind speed are shown, in a height of $10 \mathrm{~m}$. A comparison between the data observed and simulated by the model of mesoscale BRAMS is made, as well as the graphics in which were done the statistic corrections of the simulated data, for the referred sites. In Monteiro data observed only for the month of March, 1981 were recorded. In Figures (a) and (b), the comparisons between the data observed and the data of the simulation are represented, without statistical correction. In Figures (c) and (d), 


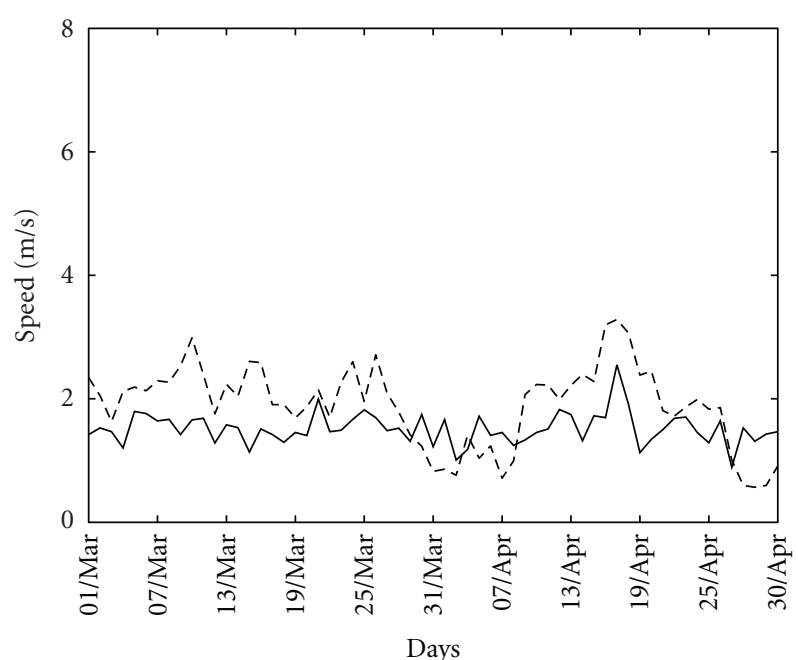

(a)

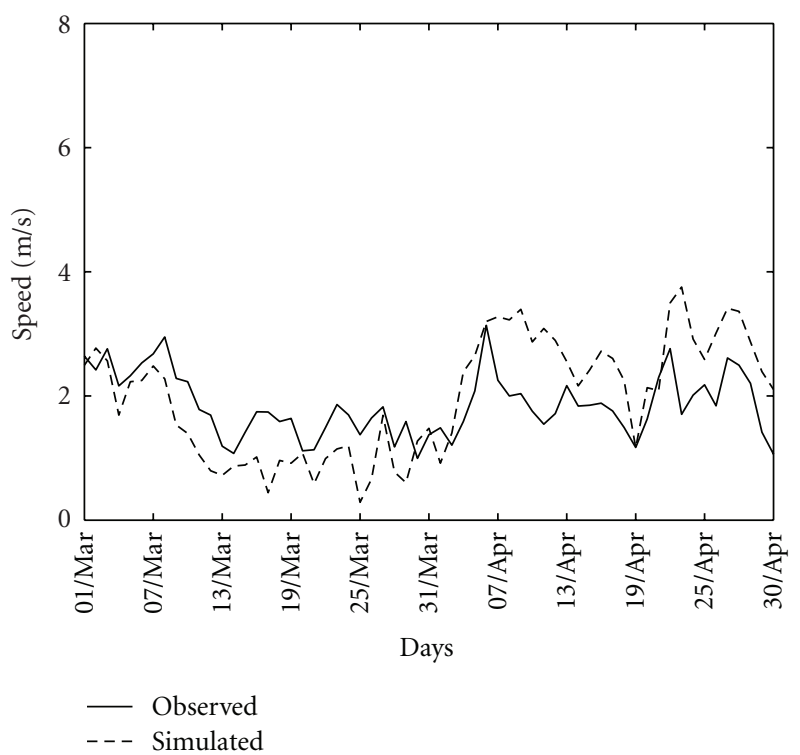

(c)

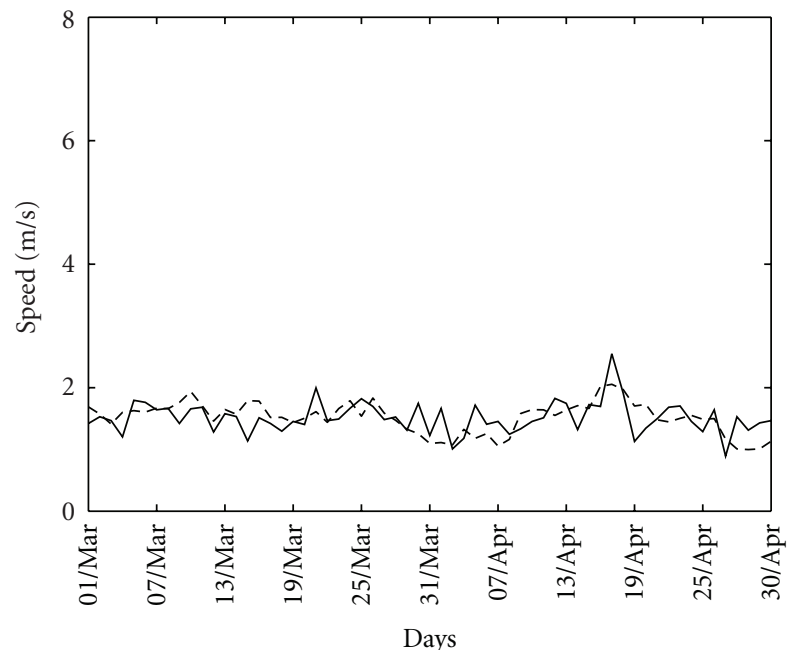

(b)

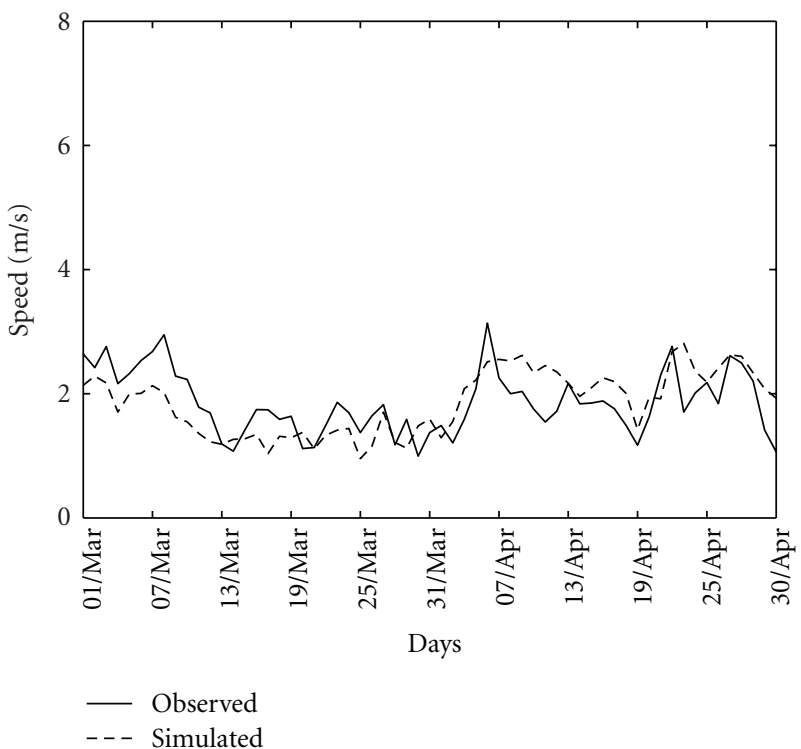

(d)

Figure 2: Comparison between the wind speed at $10 \mathrm{~m}$ high in $(\mathrm{m} / \mathrm{s})$, in months of March and April, from the observed data (solid line) and the simulated data (dashed line), for the city of São Gonçalo, (a) year 1977, (b) year 1977 with statistic correction, (c) year 1981, and (d) year 1981 with statistic correction.

there are the data observed and the data simulated by the model with statistical correction.

In Figure 2 is observed a correlation between the values of mean speed simulated and observed. In general, for the city of São Gonçalo the model overestimates the series of data observed in the year of 1977, Figure 2(a) with an inversion at the end of March and beginning of April. In the year of 1981, Figure 2(c), the model underestimates for the month of March and overestimates the month of April. A cycle well defined in 1981 in relation to 1977 can be observed, where a greater correlation is expected. In Figures 2(b) and 2(d) there are the graphics with the statistic corrections for the years 1977 and 1981, respectively, where it is shown a close relation between the simulated data and the observed data.
In Figure 3 it is observed that there is a correlation between the values of speed simulated and speed observed in all the period studied. In general, for the city of Monteiro, the model represents well the monthly cycle of March, 1981, Figure 3(c). There are not recorded data for the months of March and April, 1977, and April, 1981. The results show a slight underestimation in this period.

In Figure 4, for the city of Patos, it is observed that the simulated data follows a monthly cycle well defined, where it can be observed that, for the months of March and April of 1977, Figure 4(a), and 1981, Figure 4(c), the model underestimates the observational data, but follows a cycle well defined in comparison to the data observed. In Figures 4(b) and $4(\mathrm{~d})$ it is observed that there is a correlation between 


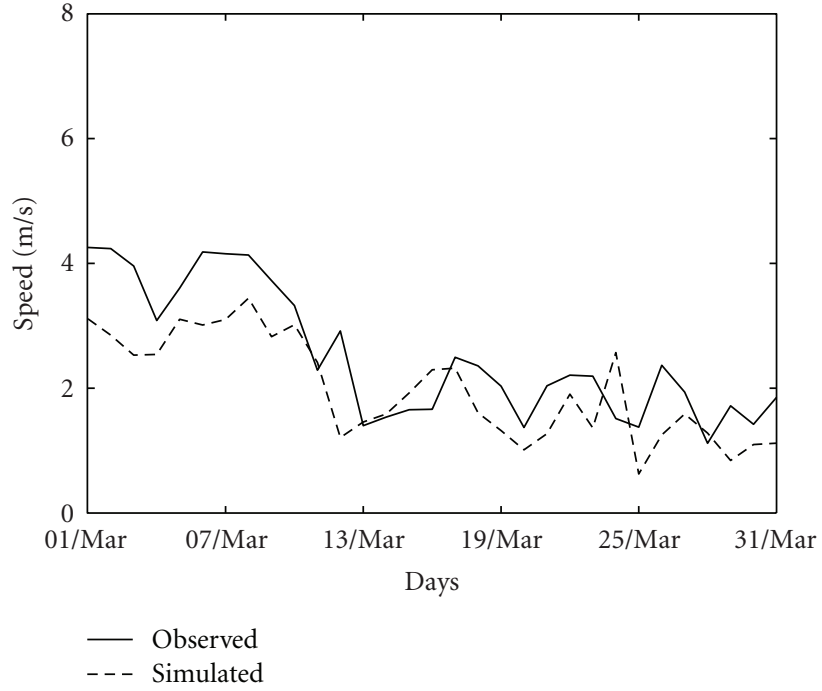

(c)

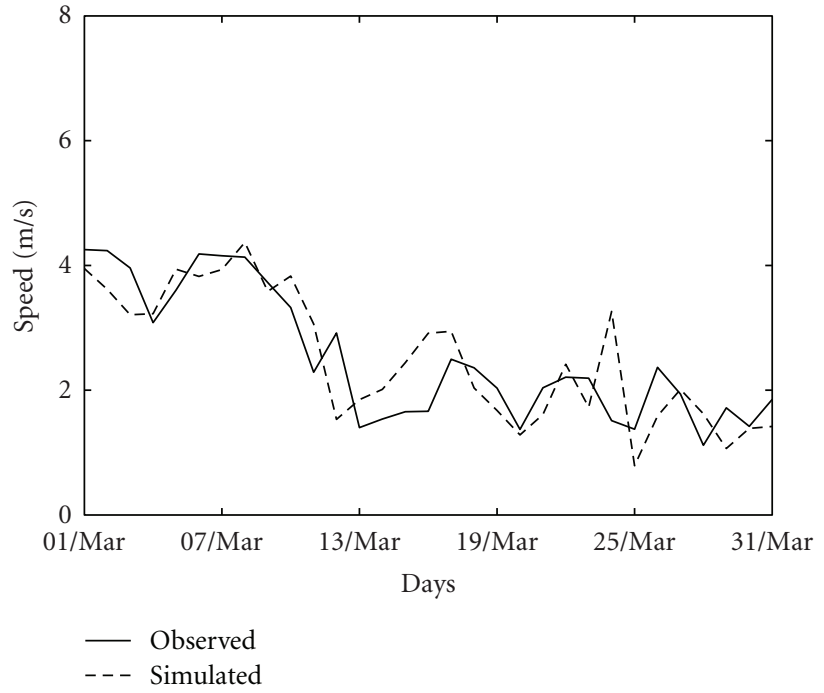

(d)

FIgURE 3: Comparison between the wind speed at $10 \mathrm{~m}$ high in $(\mathrm{m} / \mathrm{s})$, in months of March and April, from the observed data (solid line) and the simulated data (dashed line), for the city of Monteiro, (c) year 1981 and (d) year 1981 with statistical correction.

the simulated and corrected speed values and the ones observed in all this period. Maybe this happens due to the reconfiguration of the limit layer, due to the rainy period.

In Figure 5, related to Campina Grande, it can be seen that in March 1977 there is an interruption in the cycle when compared to the month of April, Figure 5(a), where it can be noted, especially in the first quarter of March, that there is a sharp reduction of the wind. For the month of April, still in Figure 5(a), it is observed that the simulated data follow a cycle well defined in relation to the observed data. It is observed that, for the month of March, 1981, Figure 5(c), the model underestimates the observational data, as well as the ones observed in all the period of March and April 1971, but with a cycle more defined for the month of March in comparison to April of the same year. It can be said that the model simulated well the month of March, 1981 for this region. In Figures 5(b) and 5(d) there are the statistical corrections, where it is shown the adjustment of the simulated data to the observed data.

In Figure 6, it is observed in João Pessoa the lack of a cycle well defined for the month of March 1977 and the existence of a monthly cycle a little more defined for the month of April of the same year, in Figure 6(a). For the year 1981, Figure 6(c), in March, there is a monthly cycle well defined, but, for the month of April of the same year, it can be observed the lack of a monthly cycle. In João Pessoa, it was verified that the simulated data in 1977 and 1981 underestimates the observational data for the month of March. And there is variability in April in relation to the overestimation and underestimation. In Figures 6(b) and 6(d) are observed the statistical corrections of the model that adjusted well to the observational data in this region.

Aiming to evaluate the performance of the results of the simulations between the series of data simulated by the model of mesoscale BRAMS and the data observed, the
Table 3: Statistical indexes for wind speed in São Gonçalo, Monteiro, Patos, Campina Grande, and João Pessoa, where EA is the mean absolute error, EQN is the mean square error, and $r$ is the correlation for the period of March 1977 and 1981.

\begin{tabular}{lcccccc}
\hline & \multicolumn{3}{c}{ March/1977 } & \multicolumn{3}{c}{ March/1981 } \\
& EA & EQM & $r$ & EA & EQM & $r$ \\
\hline São Gonçalo & 0.61 & 0.70 & $0.27^{* * *}$ & 0.53 & 0.62 & $0.83^{*}$ \\
Monteiro & - & - & - & 0.69 & 0.81 & $0.81^{*}$ \\
Patos & 0.83 & 0.96 & $0.40^{* *}$ & 1.49 & 1.66 & $0.90^{*}$ \\
Campina Grande & 2.56 & 2.62 & $0.39^{* *}$ & 1.89 & 2.03 & $0.79^{*}$ \\
João Pessoa & 0.64 & 0.74 & $0.36^{* *}$ & 0.94 & 1.17 & $0.66^{*}$ \\
\hline
\end{tabular}

* Significance to the degree of $99 \%$,** significance to the degree of $95 \%$, $* * *$ significance to the degree of $90 \%$.

Table 4: Statistical indexes for wind speed in São Gonçalo, Monteiro, Patos, Campina Grande, and João Pessoa, where EA is the absolute error, EQM is the mean absolute error, and $r$ is the correlation for the period of April 1977 and 1981.

\begin{tabular}{lcccccc}
\hline & \multicolumn{3}{c}{ April/1977 } & \multicolumn{3}{c}{ April/1981 } \\
& EA & EQM & $r$ & EA & EQM & $r$ \\
\hline São Gonçalo & 0.59 & 0.70 & $0.50^{*}$ & 0.76 & 0.89 & $0.62^{*}$ \\
Monteiro & - & - & - & - & - & - \\
Patos & 0.67 & 0.79 & $0.62^{*}$ & 1.00 & 1.12 & $0.70^{*}$ \\
Campina Grande & 1.33 & 1.51 & $0.59^{*}$ & 1.14 & 1.29 & $0.41^{* *}$ \\
João Pessoa & 0.57 & 0.68 & $0.64^{*}$ & 0.61 & 0.74 & $0.47^{*}$ \\
\hline
\end{tabular}

* Significance to the degree of $99 \%, * *$ significance to the degree of $95 \%$, $* * *$ significance to the degree of $90 \%$.

statistical indexes that can be seen on Tables 3 and 4 were obtained.

It is observed that, for the values for absolute error and mean square error, the best values are the ones nearer to zero. 


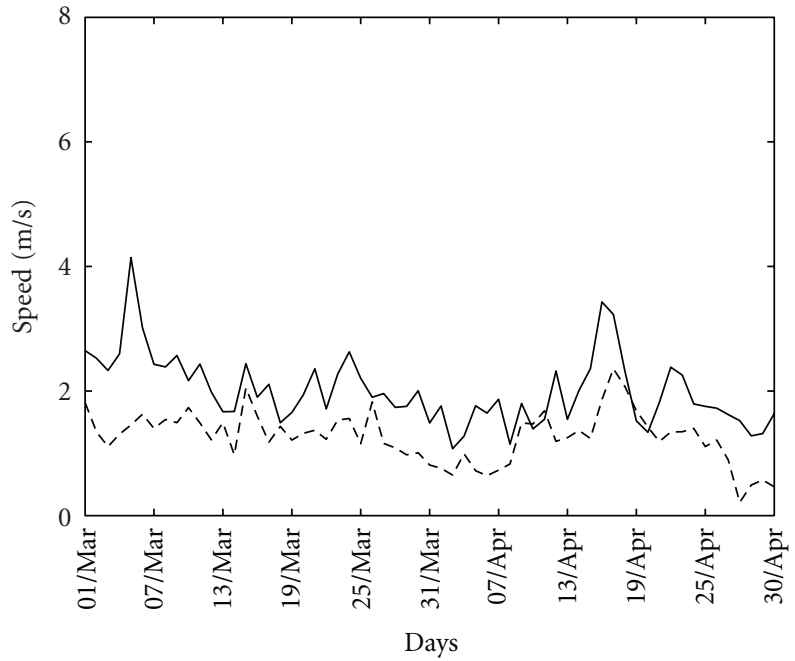

(a)

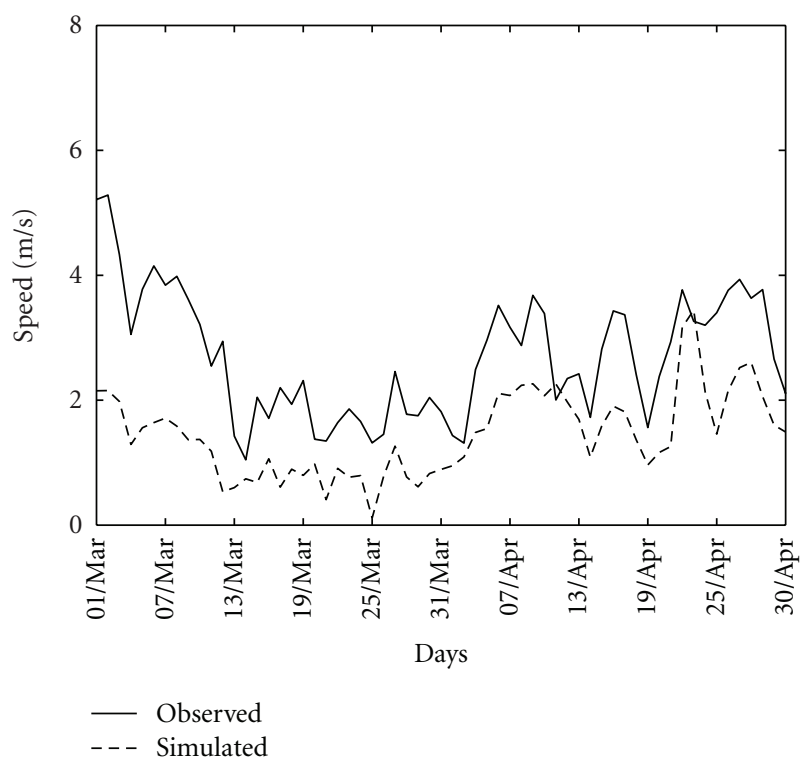

(c)

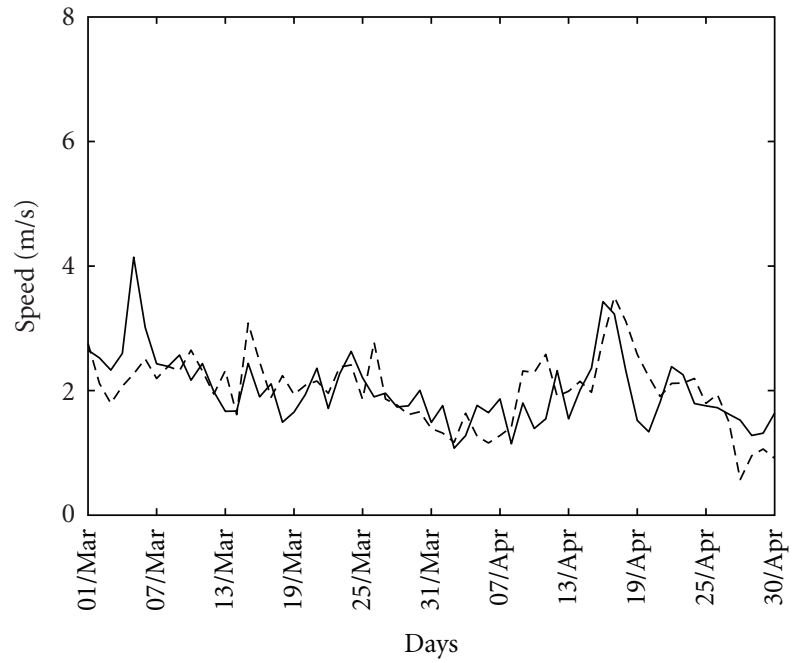

(b)

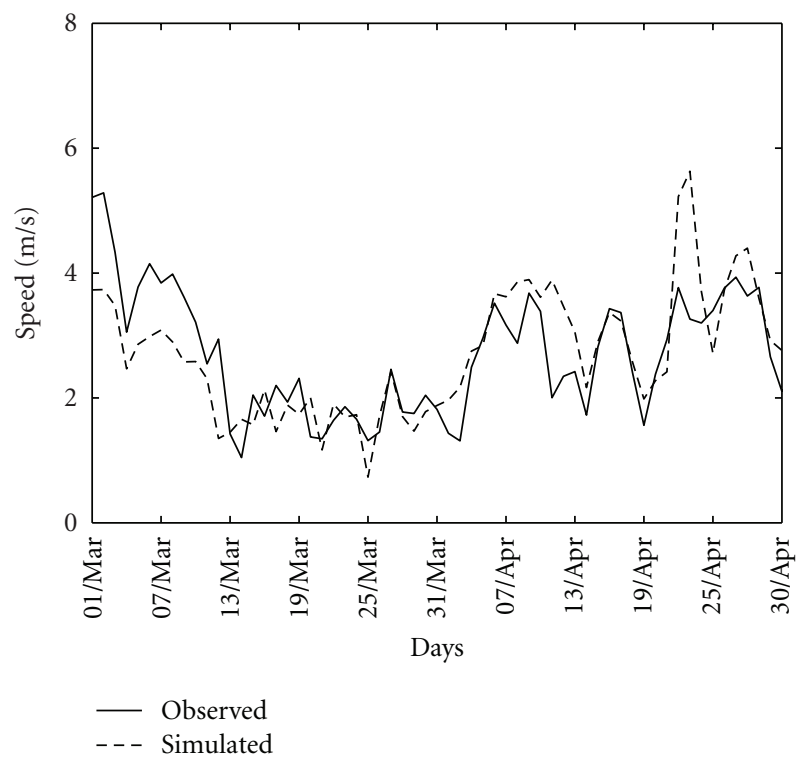

(d)

FIgURE 4: Comparison between the wind speed at $10 \mathrm{~m}$ high in $(\mathrm{m} / \mathrm{s})$, in months of March and April, from the data observed (solid line) and the simulated data (dashed line), for the city of Patos, (a) year 1977, (b) year 1977 with statistical correction, (c) year 1981 and (d) year 1981 with statistical correction.

Analyzing the month of March, 1977, it is observed that the best value for the absolute error was found in São Gonçalo station, with $0.61 \mathrm{~m} / \mathrm{s}$, while Campina Grande had a value much higher for the absolute error, with $2.56 \mathrm{~m} / \mathrm{s}$. In relation to the same period, but in the year of 1981, in the case of the absolute error, the best site continues to be São Gonçalo, with $0.53 \mathrm{~m} / \mathrm{s}$, and the worst value was, again, found in Campina Grande. For the mean square error, in 1977, the best result was in São Gonçalo and the worst in Capinha Grande, with $0.70 \mathrm{~m} / \mathrm{s}$ and $2.62 \mathrm{~m} / \mathrm{s}$, respectively, and the same happens in the year of 1981, with values equal to $0.62 \mathrm{~m} / \mathrm{s}$ for São Gonçalo and $2.03 \mathrm{~m} / \mathrm{s}$ for Campina Grande.

Observing the correlation coefficient it can be said that the best results were found for the year of 1981. Probably, a factor that determined this was the quality of the observational data, which could have been better in relation to the ones of the year 1977. The correlations for the year 1981 presented very strong, strong, and moderate coefficients. Using the test $t$ by Student, it is observed that, for the year 1981, all the correlation coefficients present statistical significance for the degree of significance of $99 \%$, while, for the year of 1977, in March, São Gonçalo station presented statistical significance for the degree of significance $90 \%$. The other sites present statistical significance for the degree of significance of $95 \%$.

Analyzing the months of April 1977 and 1981, Table 4, it is observed that the best value for the absolute error was found in João Pessoa station, for the year of 1977, 


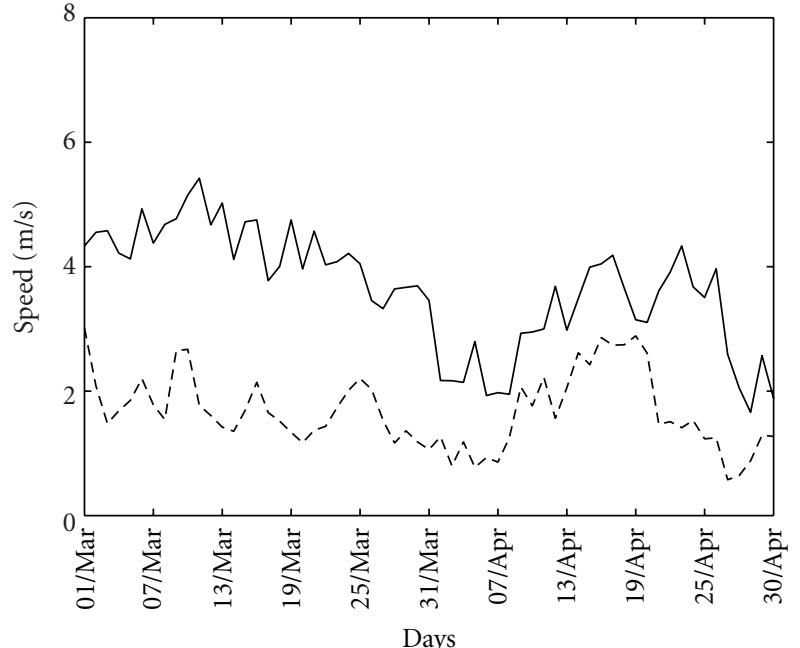

(a)

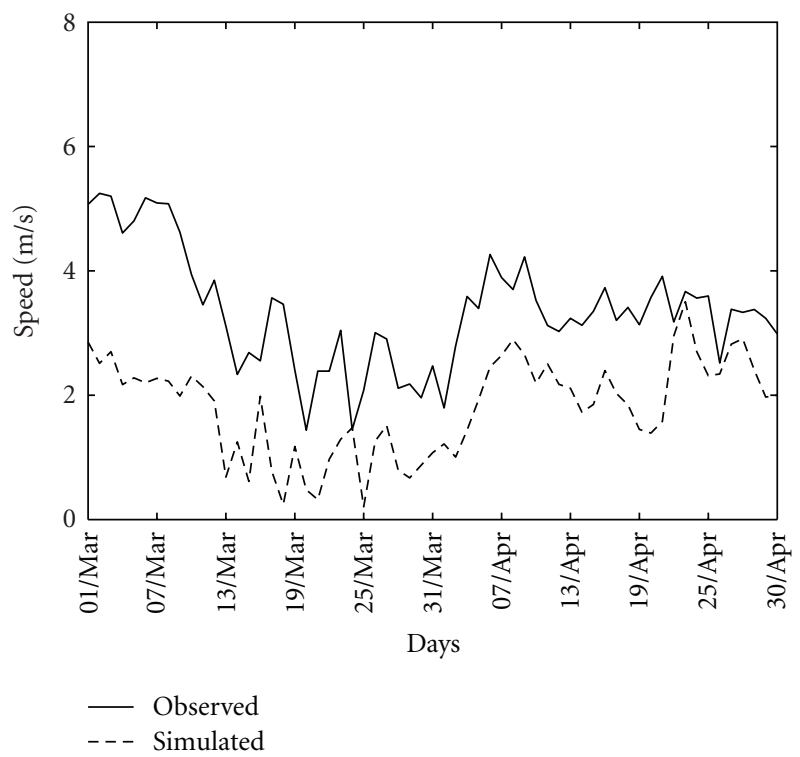

(c)

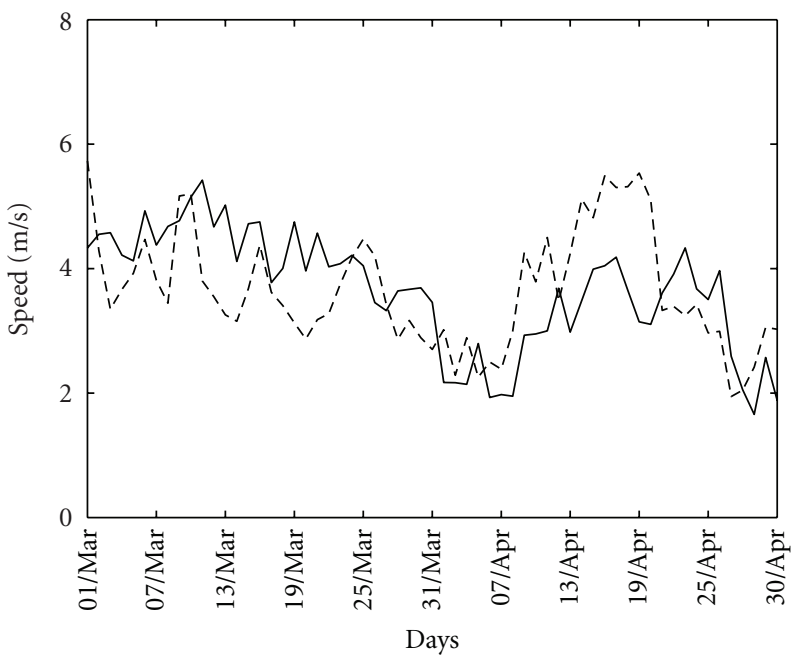

(b)

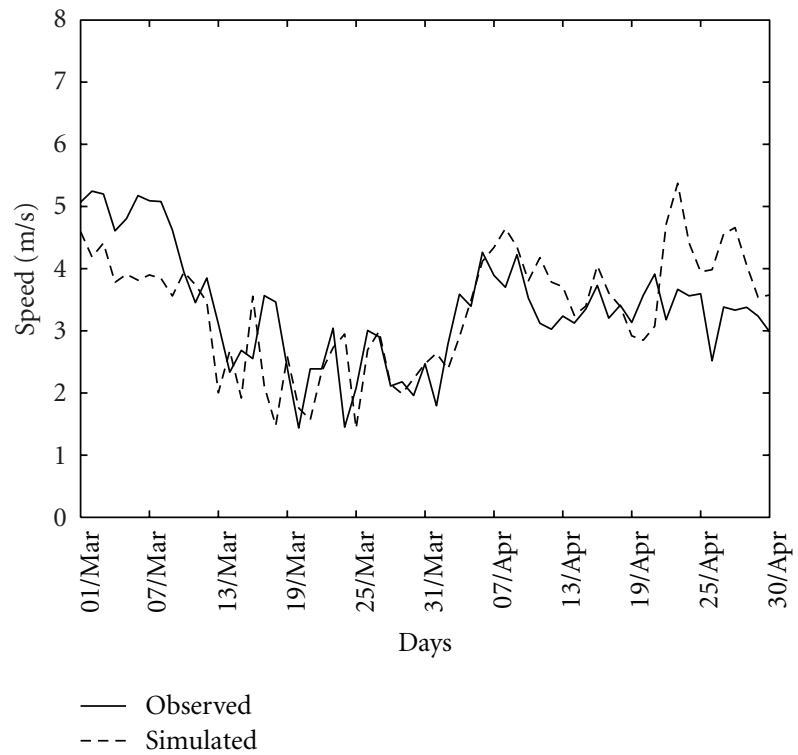

(d)

FIGURE 5: Comparison between the wind speed at $10 \mathrm{~m}$ high in $(\mathrm{m} / \mathrm{s})$, in months of March and April, from the data observed (solid line) and the simulated data (dashed line), for the city of Campina Grande, (a) year 1977, (b) year 1977 with statistical correction, (c) year 1981 and (d) year 1981 with statistical correction.

with $0.57 \mathrm{~m} / \mathrm{s}$, while Campina Grande obtained the higher value, with $1.33 \mathrm{~m} / \mathrm{s}$. In the same period, but in 1981, in the case of the absolute error, the best site continues to be João Pessoa, with $0.61 \mathrm{~m} / \mathrm{s}$, and the worst value, again, was found in Campina Grande, with $1.14 \mathrm{~m} / \mathrm{s}$. It can be observed that, for both the months of March and April, in the two years studied, the Campina Grande station obtained higher values of absolute errors. For the mean square error, the best result continues to be in João Pessoa, for the year of 1977, followed by São Gonçalo, Patos, and Campina Grande. In Monteiro were not recorded observational data. The same happens in 1981.

Observing the correlation coefficient, it can be said that the results, both in 1977 and 1981, in the month referred, were close. The correlations for the year of 1977 present moderate coefficients in all stations, while, in 1981, all stations obtained moderate correlations, as was observed in 1977. Using the test $t$ by Student, it is observed that for the year 1977 all the correlation coefficients presented statistical significance, to the degree of significance of $99 \%$, while in 1981, for the month of April, the Campina Grande station presented statistical significance to the degree of significance of $95 \%$. The other sites present statistical significance to the degree of significance of $99 \%$.

In relation to the wind direction studied, graphics of the Compass Rose was constructed, from Figures 7 to 11, for the five sites, in the period of March, April, September, and October, and a qualitative comparison is made between 


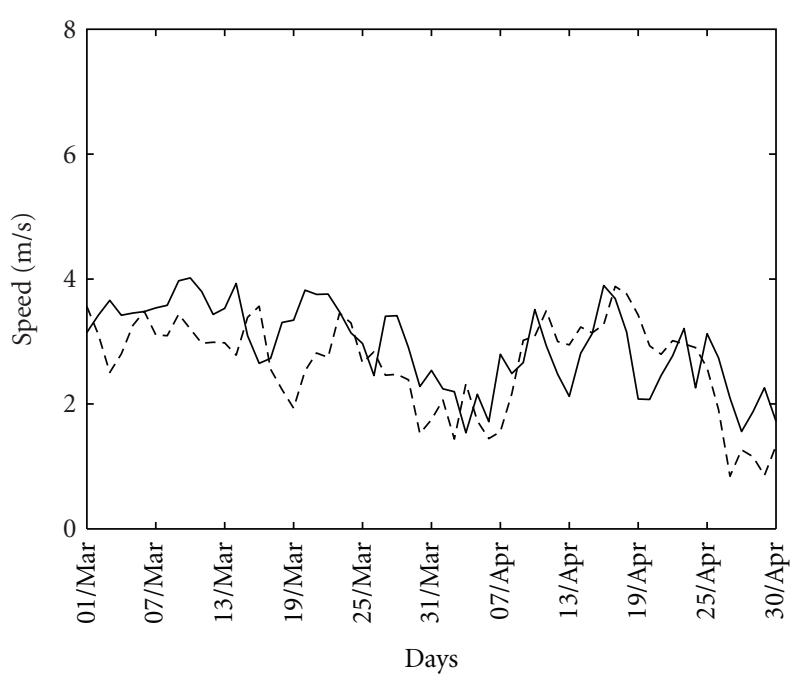

(a)

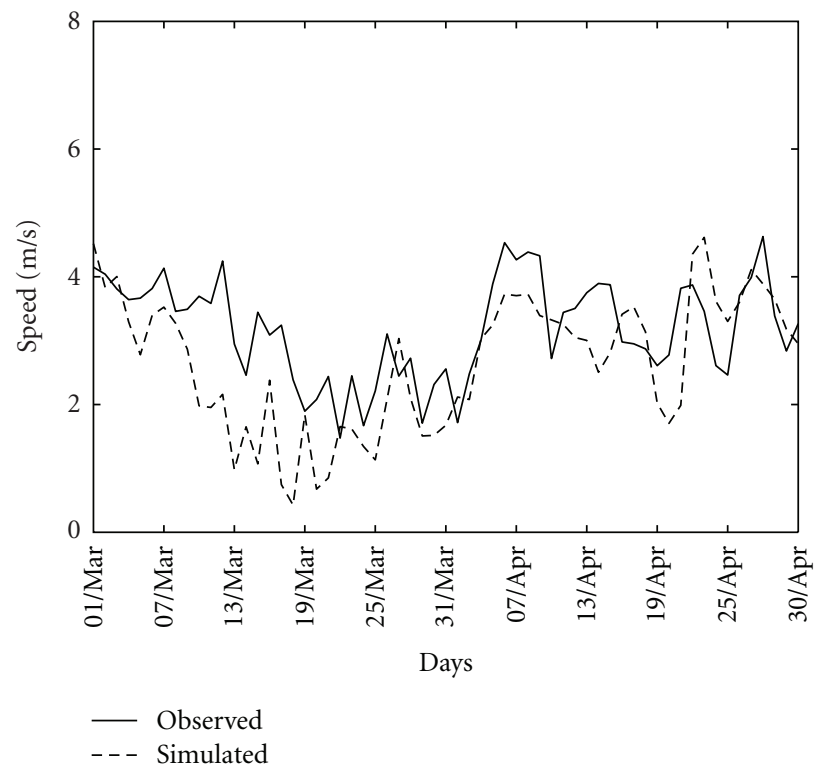

(c)

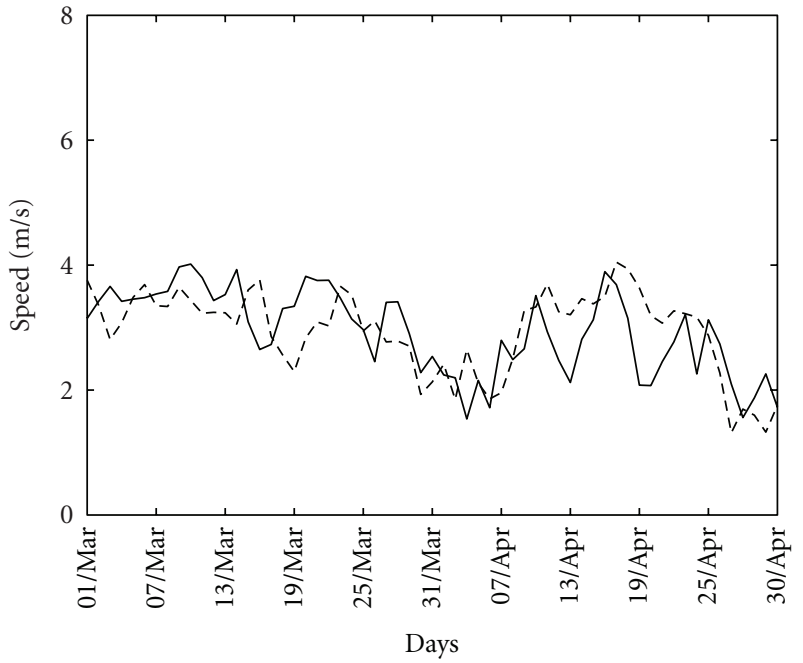

(b)

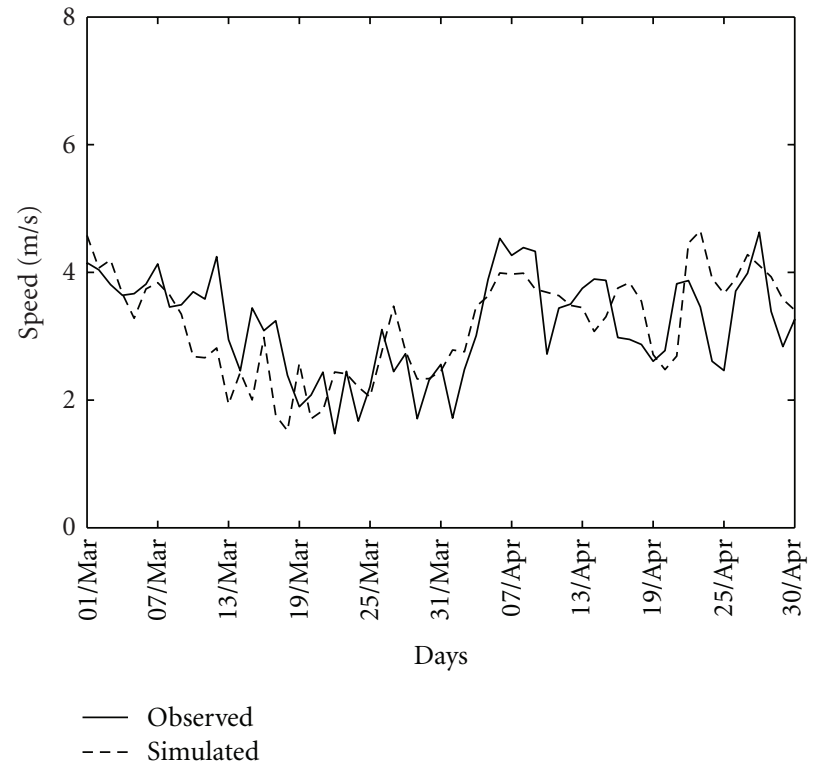

(d)

Figure 6: Comparison between the wind speed at $10 \mathrm{~m}$ high in $(\mathrm{m} / \mathrm{s})$, in months of March and April, from the data observed (solid line) and the simulated data (dashed line), for the city of João Pessoa, (a) year 1977, (b) year 1977 with statistical correction, (c) year 1981, and (d) year 1981 with statistical correction.

the direction in the observational period and the period of the simulation, to identify if the model simulated well the sites studied, in relation to the variable direction. In Figure 7, it is observed that, along the period studied, 1977 and 1981, the wind was predominantly east, varying from $45^{\circ}$ to $135^{\circ}$, that is, varying from northeast to southeast. In North direction, it is observed that there is a high percentage for the São Gonçalo station, probably due to problems in obtaining the data, or calm. The higher percentages of wind speed occurred in the rate from $3.6 \mathrm{~m} / \mathrm{s}$ to $5.7 \mathrm{~m} / \mathrm{s}$. A resemblance can be observed between the simulated and observed data, especially in 1981.

In Figure 8, it can be observed that wind was predominantly east, varying from $45^{\circ}$ to $135^{\circ}$, that is, varying from northeast to southeast, as observed in São Gonçalo. In north direction a high percentage for the observational data for the year of 1981 is verified, Figure 8(c), probably due to problems in obtaining data or calm. The higher percentages of wind speed occurred in the rate from $3.6 \mathrm{~m} / \mathrm{s}$ to $5.7 \mathrm{~m} / \mathrm{s}$ and $5.7 \mathrm{~m} / \mathrm{s}$ to $8.8 \mathrm{~m} / \mathrm{s}$. It can be observed that there is a resemblance between the simulated and observed data, that is, in both São Gonçalo and Monteiro stations the model seems to be simulated well the wind direction.

In Figure 9, it is observed that wind was predominantly east, varying from $90^{\circ}$ to $135^{\circ}$, that is, varying from east to southeast. In north direction, it is observed that there is a high percentage for the observational data, for the year of 1977, Figure 9(a). The higher percentage of wind speed 

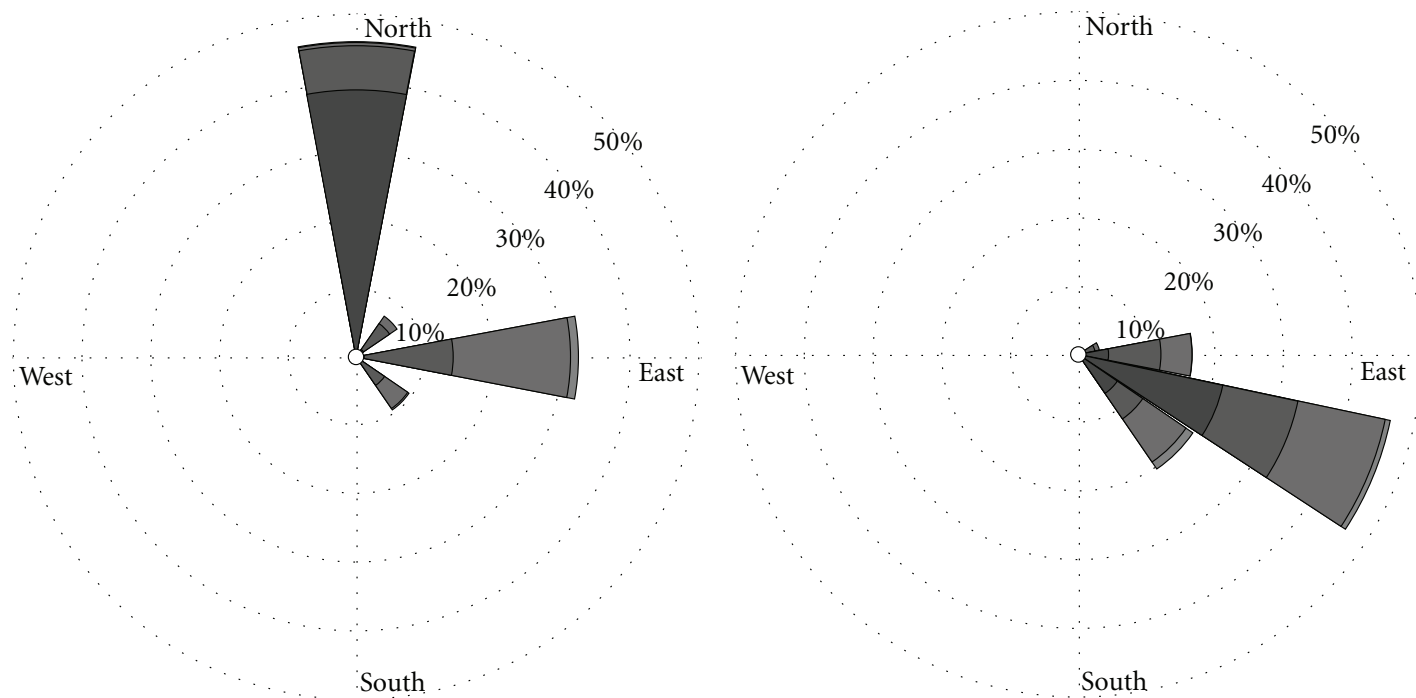

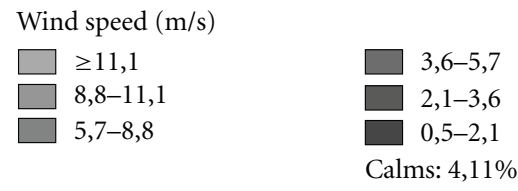

(a)

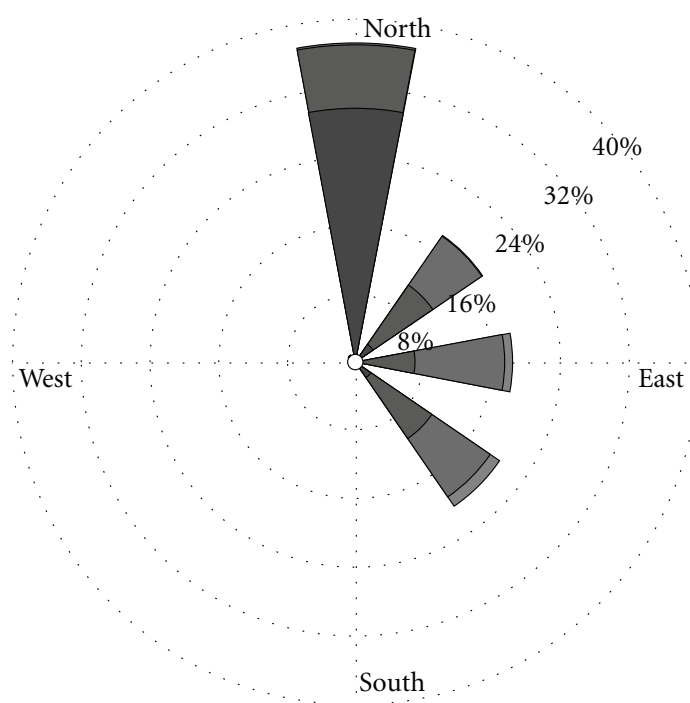

Wind speed $(\mathrm{m} / \mathrm{s})$

$\begin{array}{ll}\square \geq 11,1 & \\ \square, 8-11,1 & \\ \square & 2,1-3,6 \\ 5,7-8,8 & \\ & 0,5-2,1 \\ & \text { Calms: } 3,9 \%\end{array}$

(c)

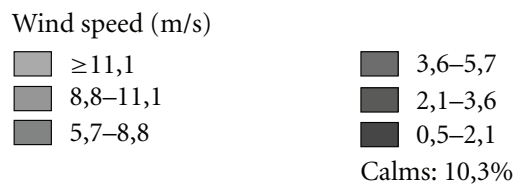

(b)

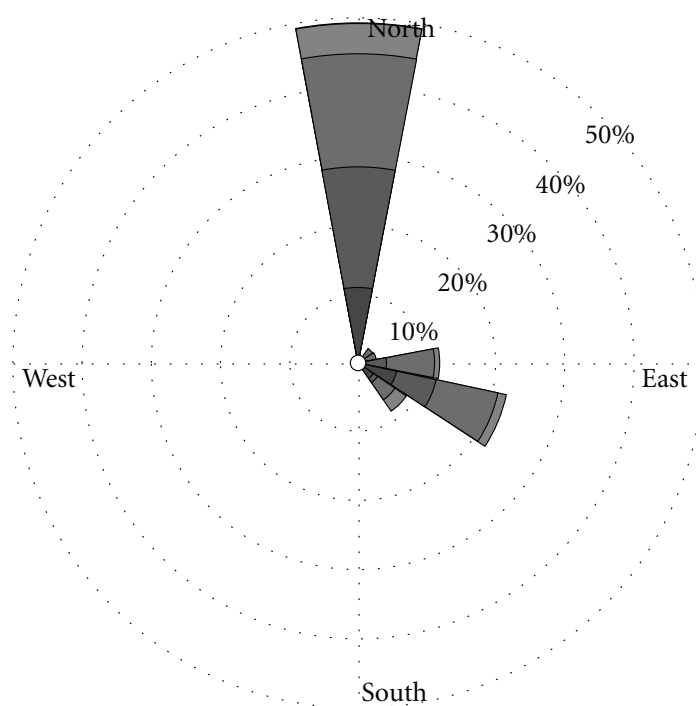

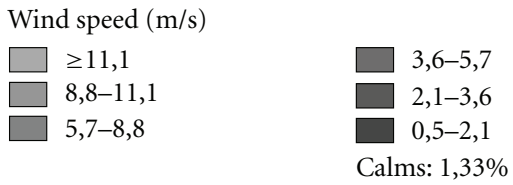

(d)

FIGURE 7: Compass rose, speed, and direction of wind at $10 \mathrm{~m}$ high from the surface for the months of March, April, September, and October measured in São Gonçalo: (a) observational data for the year 1977, (b) simulated data for the year 1977, (c) observational data for the year 1981, and (d) simulated data for the year 1981. 

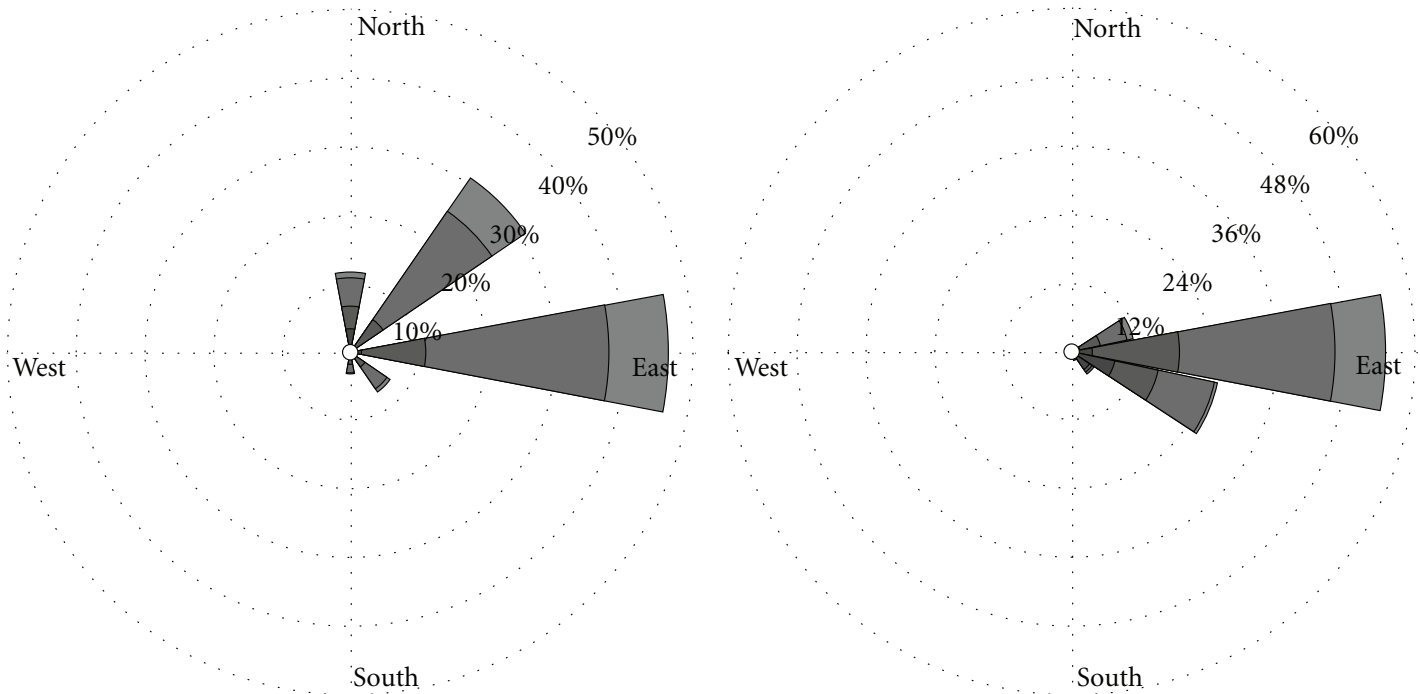
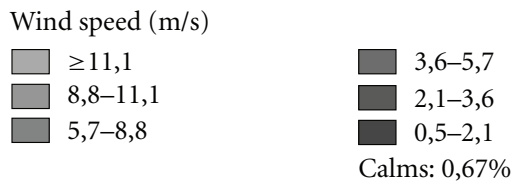

(a)

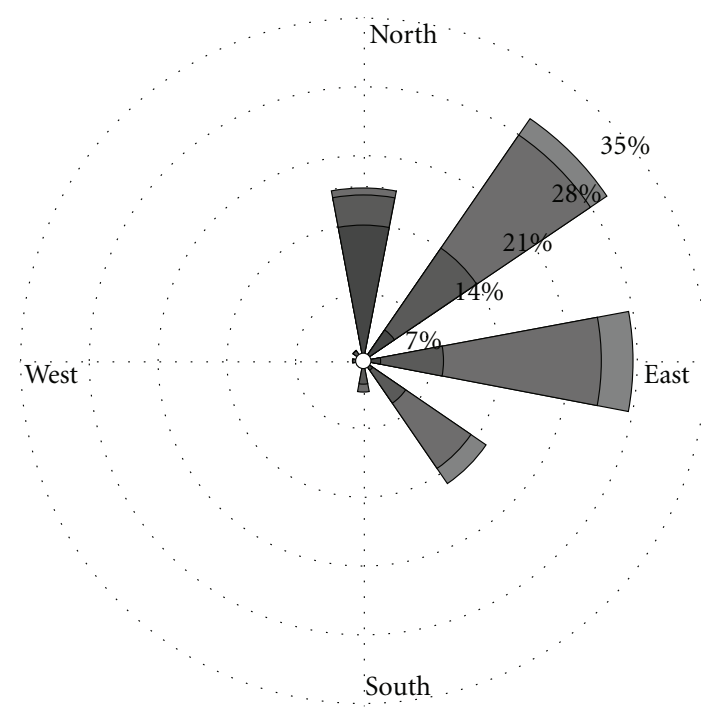

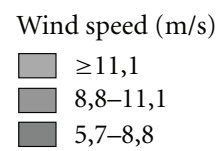

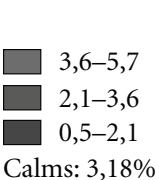

(c)

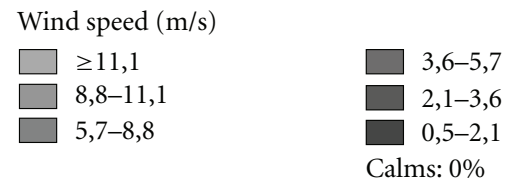

(b)

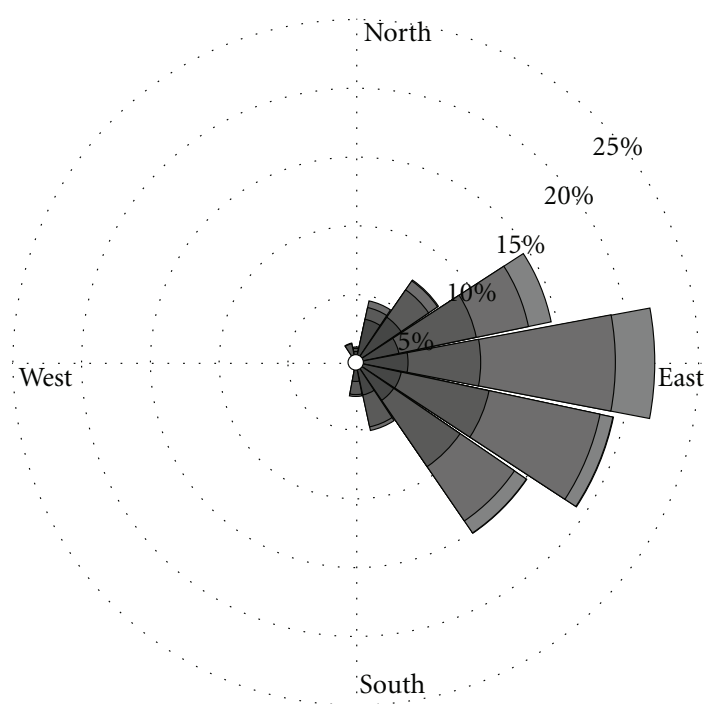

Wind speed $(\mathrm{m} / \mathrm{s})$
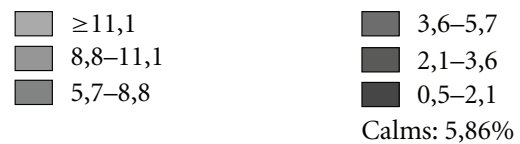

(d)

Figure 8: Compass rose, speed, and direction of wind at $10 \mathrm{~m}$ high from the surface for the months of March, April, September, and October measured in Monteiro: (a) observational data for the year 1977, (b) simulated data for the year 1977, (c) observational data for the year 1981, and (d) simulated data for the year 1981. 

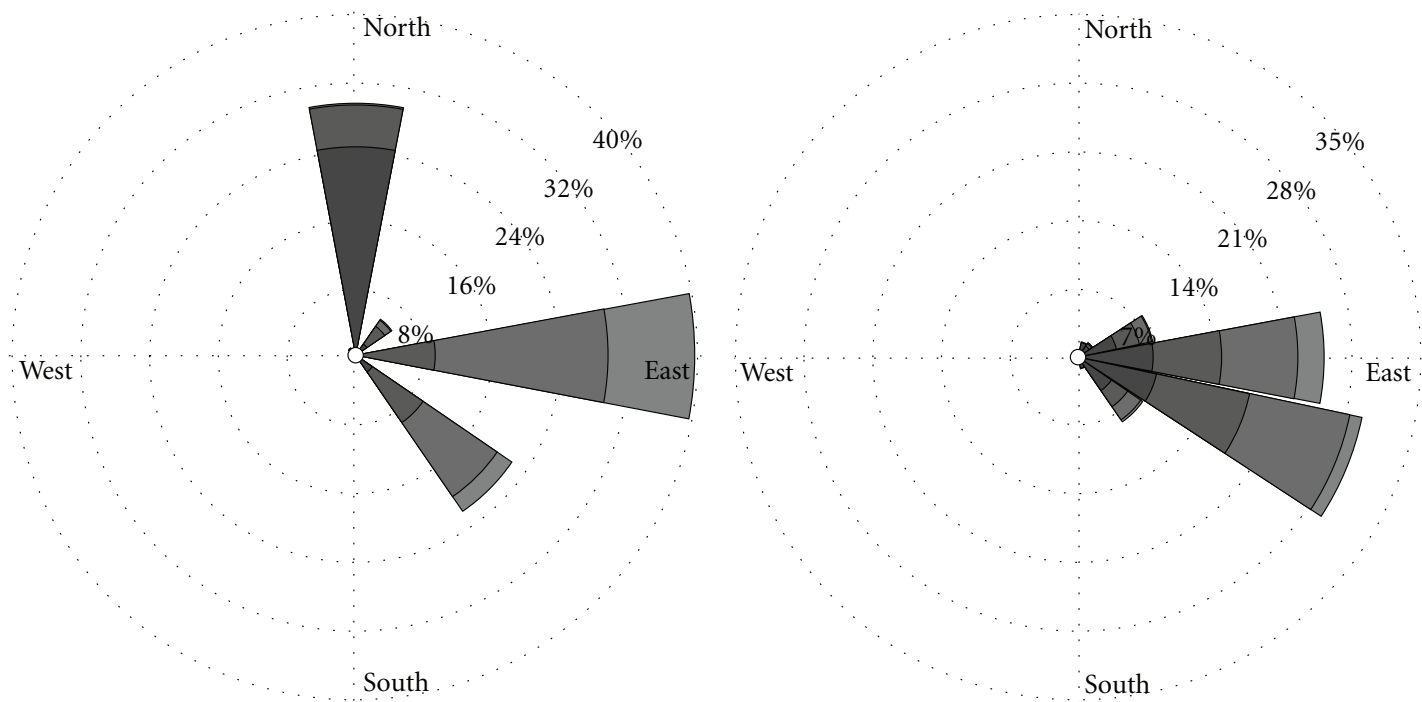

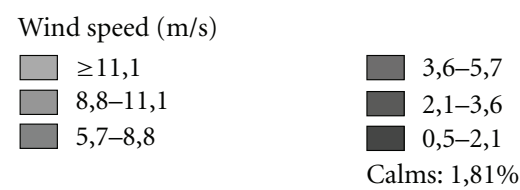

(a)

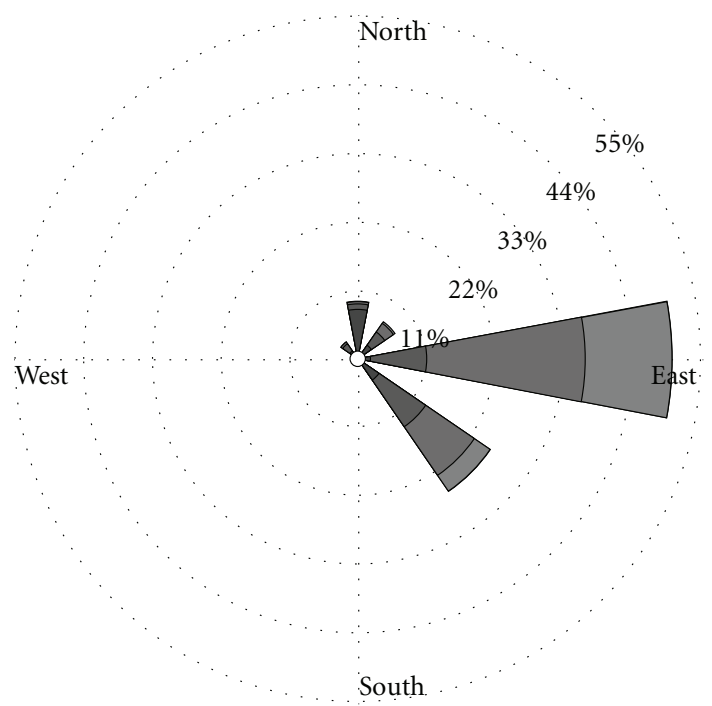

Wind speed $(\mathrm{m} / \mathrm{s})$

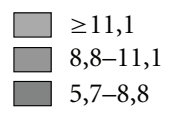

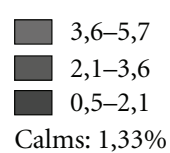

(c)
Wind speed $(\mathrm{m} / \mathrm{s})$

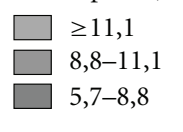

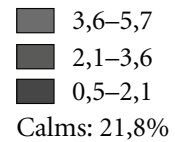

(b)

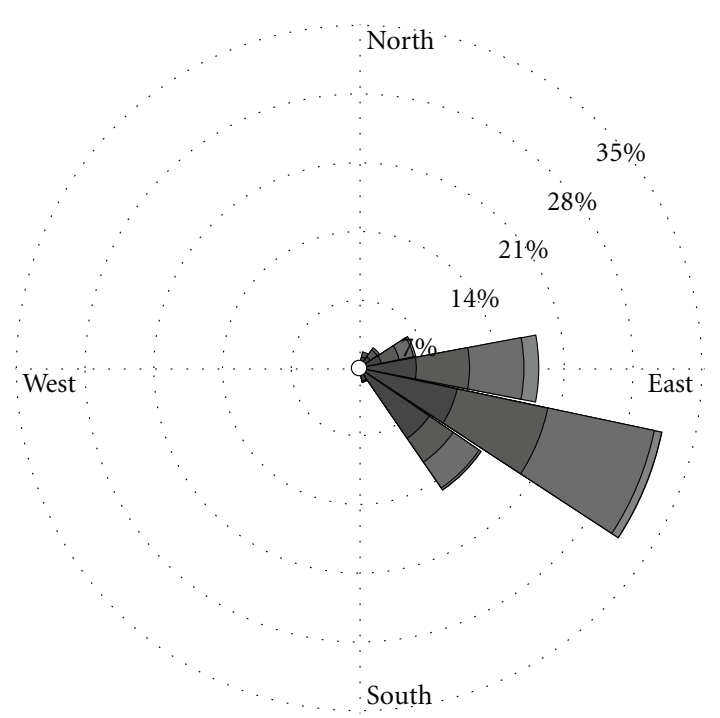

Wind speed $(\mathrm{m} / \mathrm{s})$

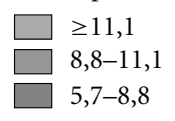

$\square$ 8,8-11,1

$5,7-8,8$

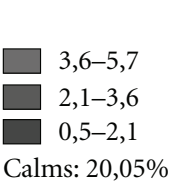

(d)

Figure 9: Compass rose, speed, and direction of wind at $10 \mathrm{~m}$ high from the surface for the months of March, April, September, and October measured in Patos: (a) observational data for the year 1977, (b) simulated data for the year 1977, (c) observational data for the year 1981, and (d) simulated data for the year 1981. 

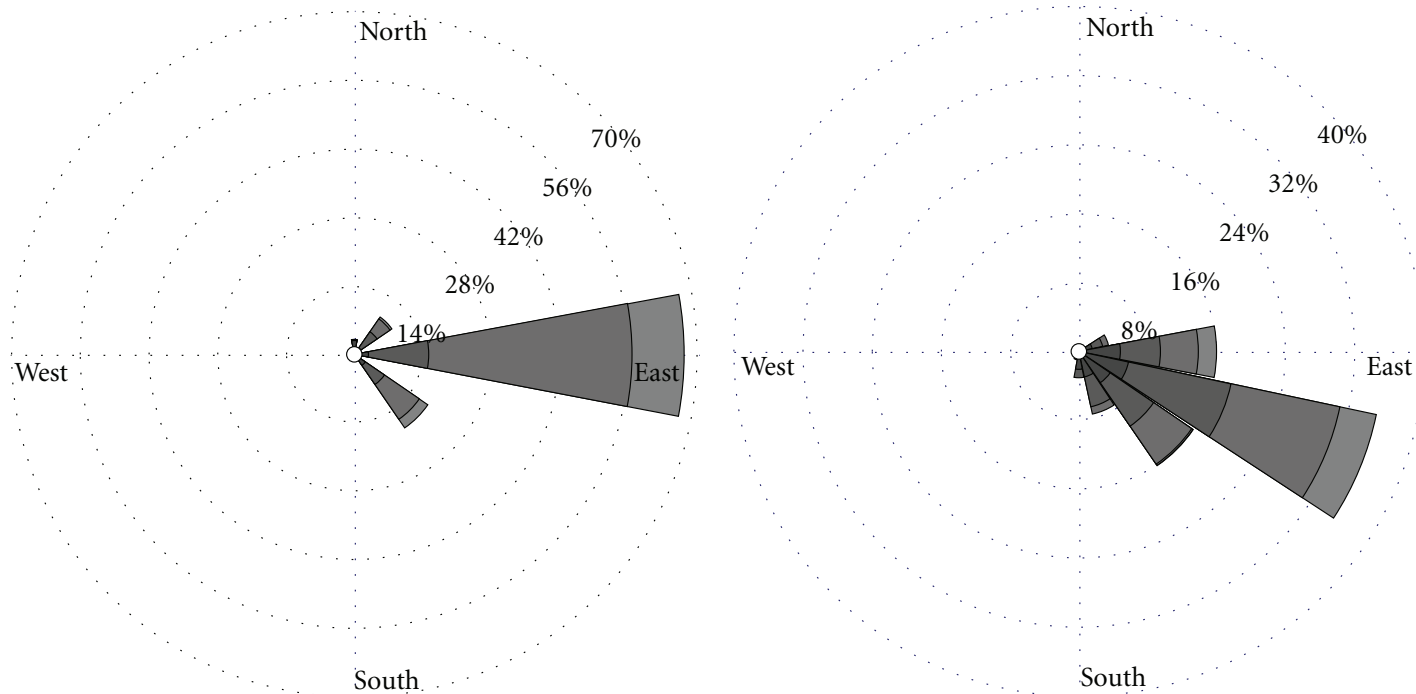

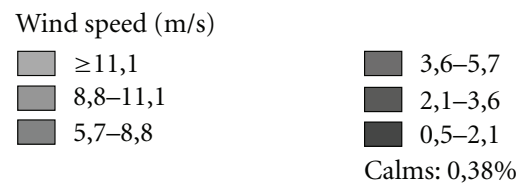

(a)

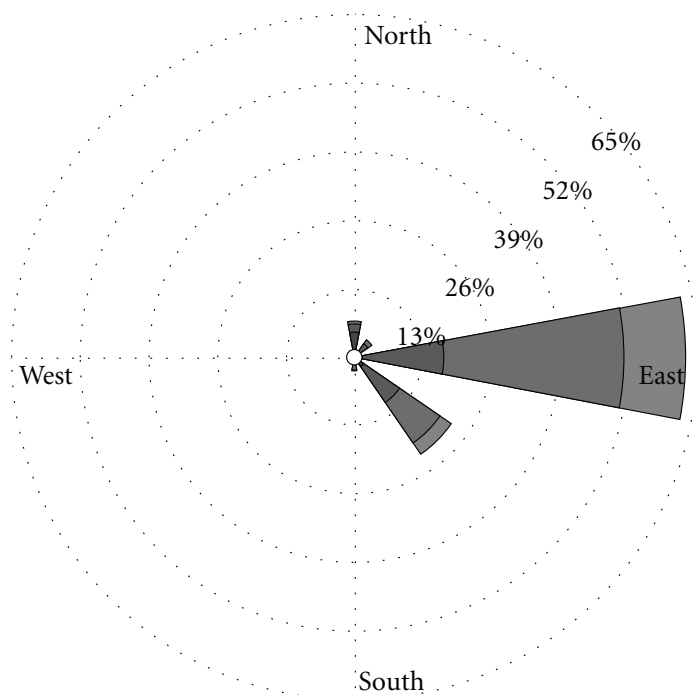

Wind speed $(\mathrm{m} / \mathrm{s})$

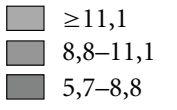
$3,6-5,7$
$2,1-3,6$
$0,5-2,1$

Calms: 0,68\%

(c)
Wind speed $(\mathrm{m} / \mathrm{s})$

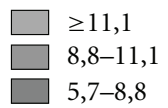
$3,6-5,7$
2,1-3,6
$0,5-2,1$
Calms: $14,44 \%$

(b)

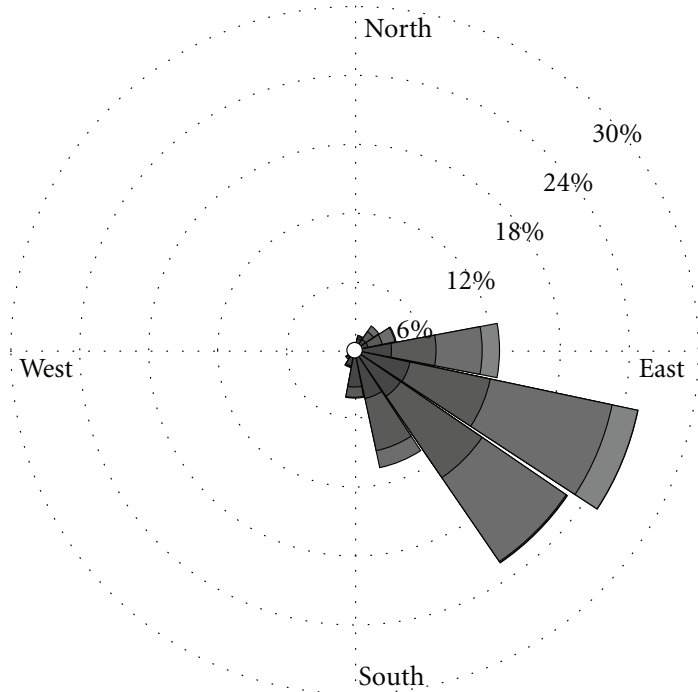

Wind speed $(\mathrm{m} / \mathrm{s})$
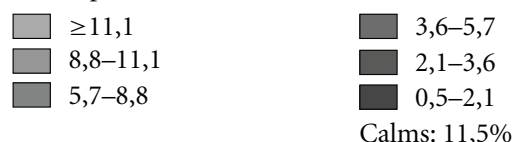

(d)

FIgURE 10: Compass rose, speed, and direction of wind at $10 \mathrm{~m}$ high from the surface for the months of March, April, September, and October measured in Campina Grande: (a) observational data for the year 1977, (b) simulated data for the year 1977, (c) observational data for the year 1981, and (d) simulated data for the year 1981. 

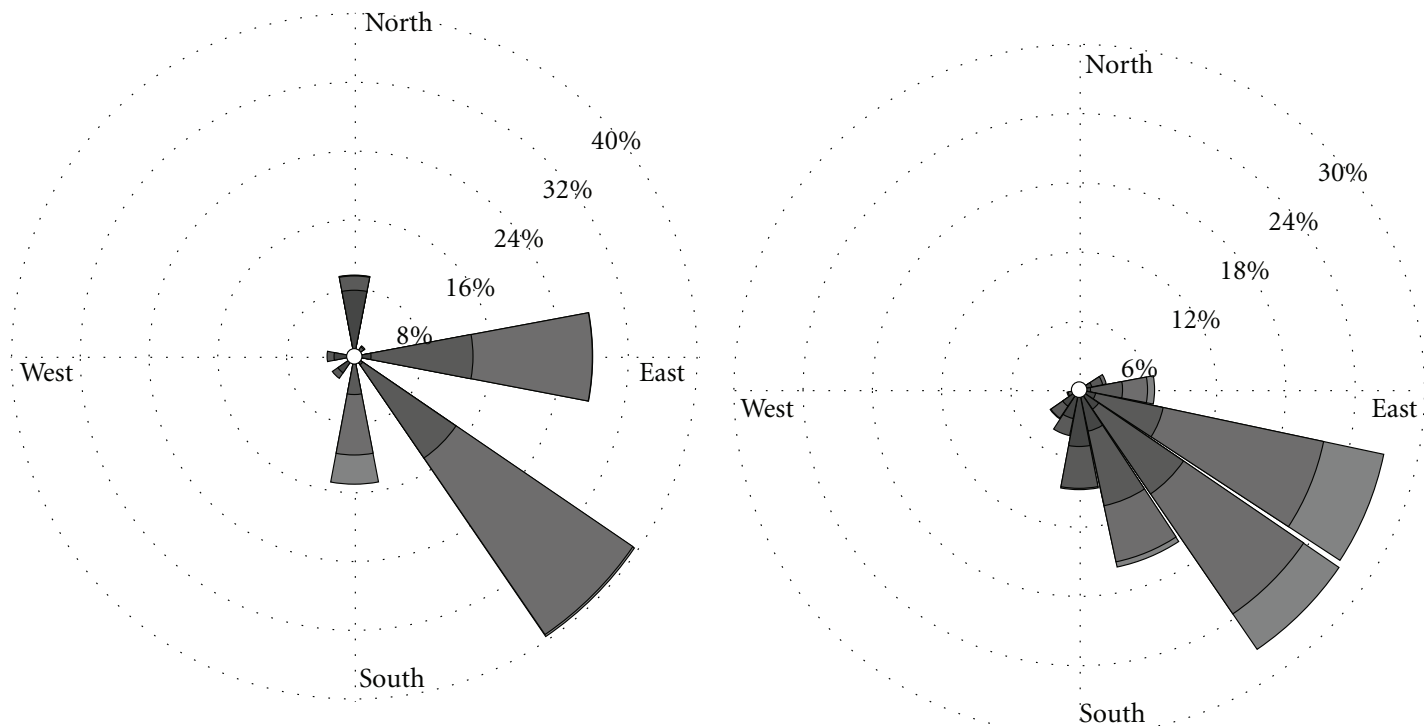

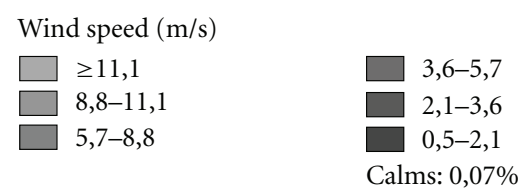

(a)

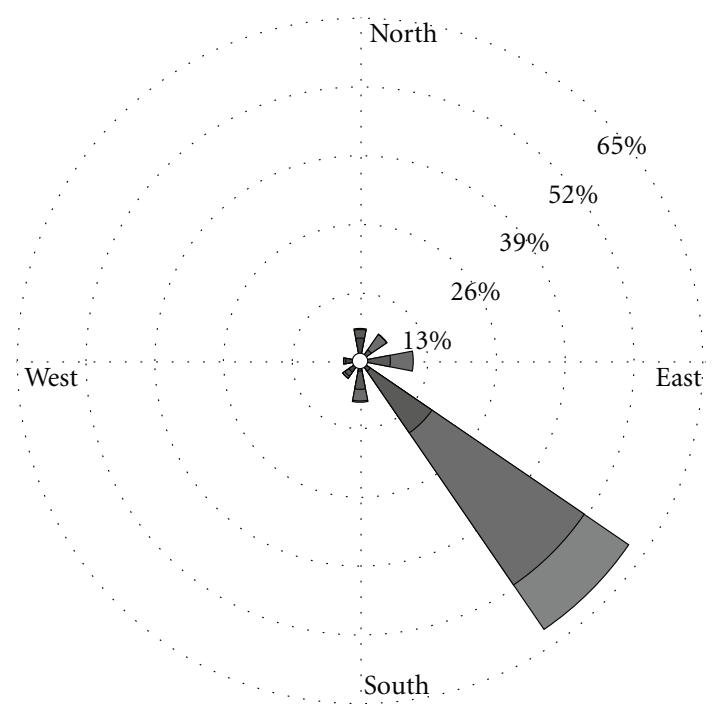

Wind speed $(\mathrm{m} / \mathrm{s})$

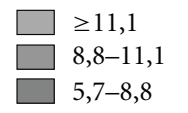

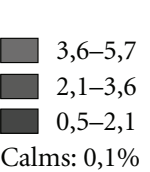

(c)

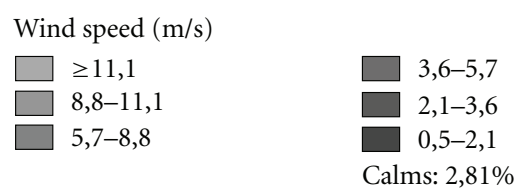

(b)

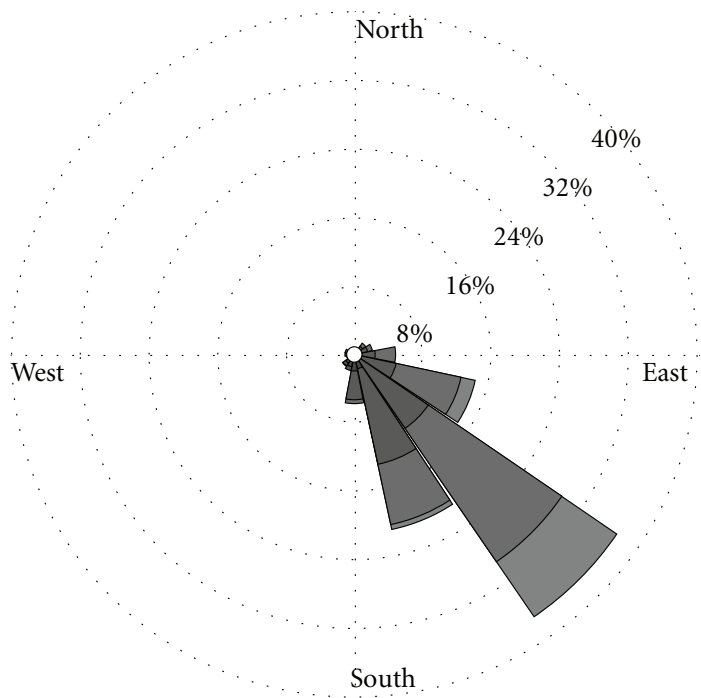

Wind speed $(\mathrm{m} / \mathrm{s})$
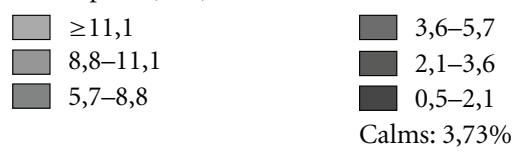

(d)

FIgURE 11: Compass rose, speed, and direction of wind at $10 \mathrm{~m}$ high from the surface for the months of March and April measured in João Pessoa: (a) observational data for the year 1977, (b) simulated data for the year 1977, (c) observational data for the year 1981, and (d) simulated data for the year 1981. 


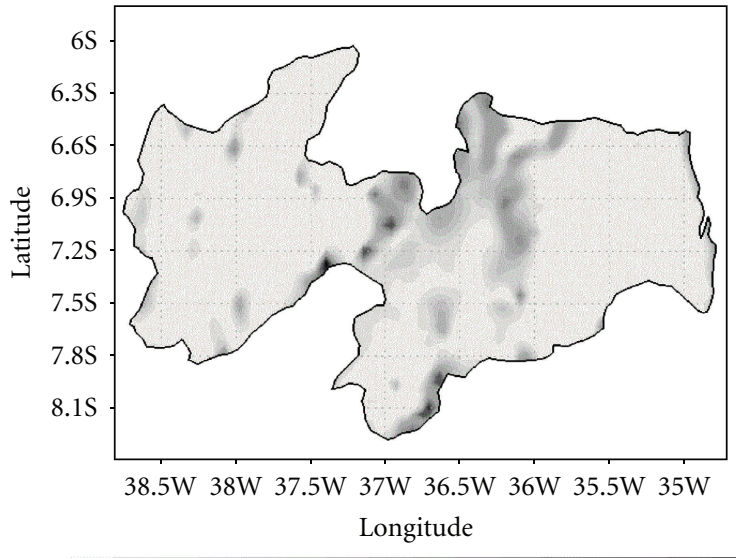

$\begin{array}{lllllllllllllll}10 & 15 & 20 & 25 & 30 & 40 & 45 & 50 & 55 & 60 & 70 & 75 & 80 & 85 & 90\end{array}$

(a)

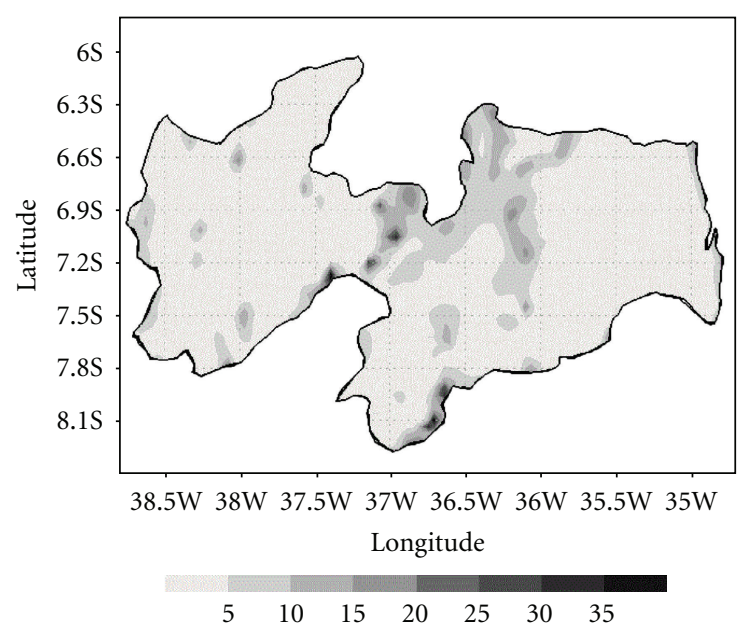

(c)

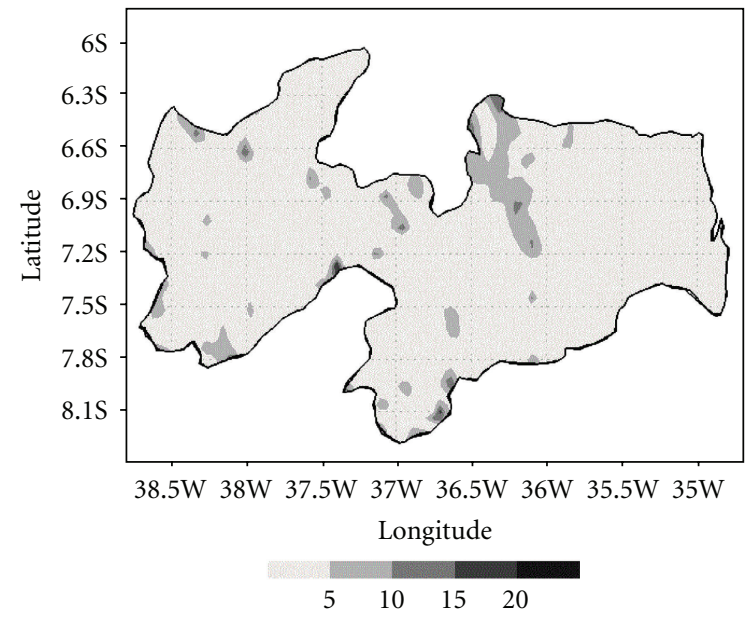

(b)

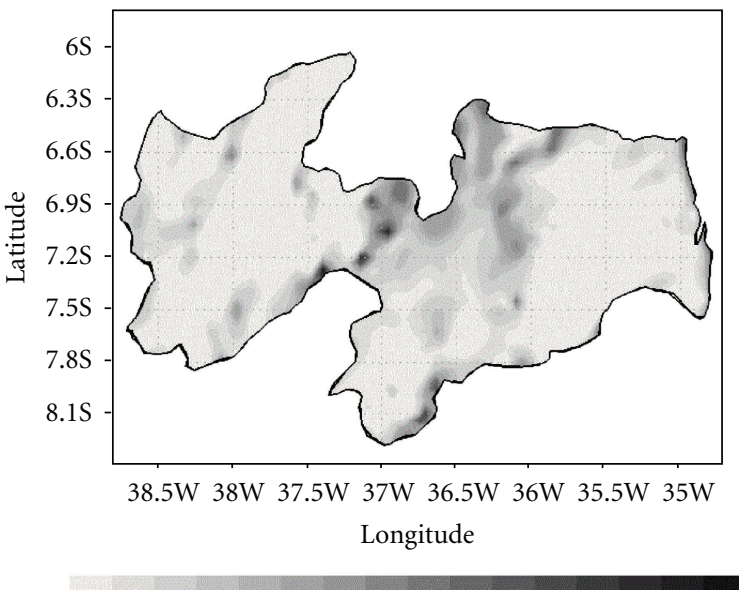

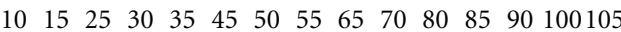

(d)

Figure 12: Mean wind power density in $\left(\mathrm{W} / \mathrm{m}^{2}\right)$ for the State of Paraíba for the following period: (a) March 1977, (b) March 1981, (c) April 1977, and (d) April 1981.

occurred in the rate from $2.1 \mathrm{~m} / \mathrm{s}$ to $3.6 \mathrm{~m} / \mathrm{s}$ and $3.6 \mathrm{~m} / \mathrm{s}$ to $5.7 \mathrm{~m} / \mathrm{s}$, and it can be observed that there is a resemblance between the simulated and observed data.

In Figure 10 is the Campina Grande station, where the wind were predominantly east, varying from $45^{\circ}$ to $135^{\circ}$, that is, varying from northeast to southeast, for the observational data, Figures 10(a) and 10(c), while for the data simulated by the model the wind was predominantly southeast, varying from east to southeast. The higher percentages of wind speed occurred in rates from $2.1 \mathrm{~m} / \mathrm{s}$ to $3.6 \mathrm{~m} / \mathrm{s}, 3.6 \mathrm{~m} / \mathrm{s}$ to $5.7 \mathrm{~m} / \mathrm{s}$, and $5.7 \mathrm{~m} / \mathrm{s}$ to $8.8 \mathrm{~m} / \mathrm{s}$. It can be observed that there is a resemblance between the simulated data and the observed data, having in mind that the observational data only reach exact values, such as $0^{\circ}, 45^{\circ}, 90^{\circ}, 135^{\circ}, 180^{\circ}, 225^{\circ}, 270^{\circ}$, $315^{\circ}$ and, at last, $360^{\circ}$, while the model can reach any value between $0^{\circ}$ and $360^{\circ}$.

In Figure 11 is the João Pessoa station where the wind was predominantly southeast, varying from $90^{\circ}$ to $180^{\circ}$, that is, varying from east to southeast. The higher percentages of wind speed occurred in rates from $2.1 \mathrm{~m} / \mathrm{s}$ to $3.6 \mathrm{~m} / \mathrm{s}, 3.6 \mathrm{~m} / \mathrm{s}$ to $5.7 \mathrm{~m} / \mathrm{s}$, and $5.7 \mathrm{~m} / \mathrm{s}$ to $8.8 \mathrm{~m} / \mathrm{s}$. It can be observed that there is a resemblance between the simulated and observed data. It is important to highlight that, in order to have a better notion in relation to the adjustment between the observational data and the data simulated by the model, it is necessary to have a quantitative analysis of the data. Thus, it is necessary to use the statistics indexes described in the methodology of this research.

In Figures 12 and 13 there is the map of the State of Paraíba for the mean wind power density with the localization of the stations used for the period considered rainy in the region, that is, in the months of March and April, Figure 12, and for the dry period in the region, that is, for the months of September and October, Figure 13, in years 1977 and 1981.

It can be observed in Figure 12 that the higher values of density of wind power were found in the mesoregion of 


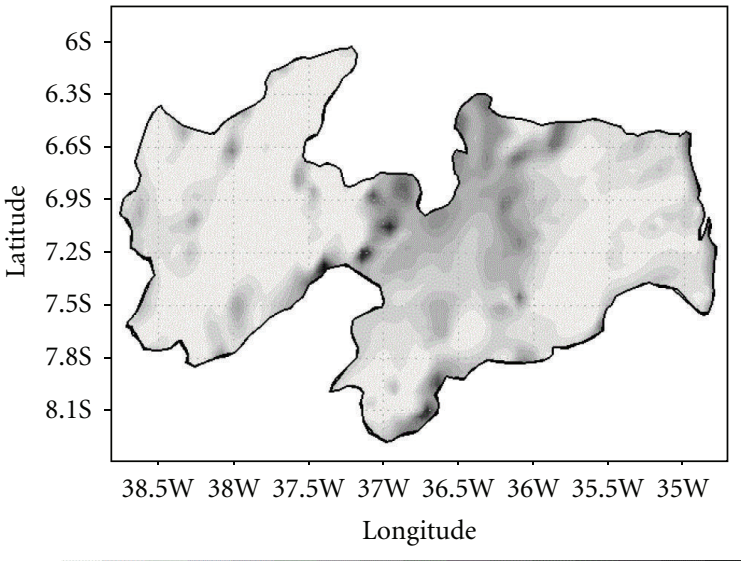

$\begin{array}{lllllllll}15 & 25 & 35 & 45 & 60 & 70 & 80 & 90105115125135150160170\end{array}$

(a)

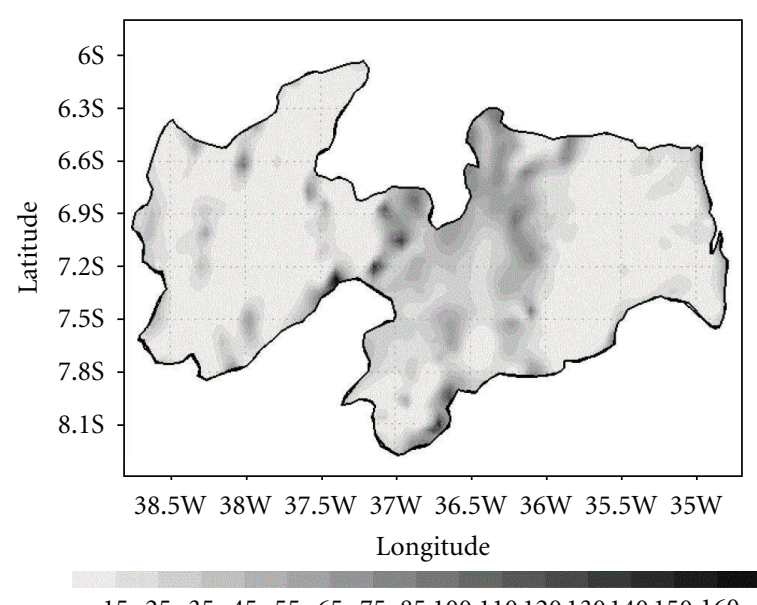

$15 \quad 25 \quad 3545 \quad 55 \quad 65 \quad 75 \quad 85100110120130140150160$

(c)

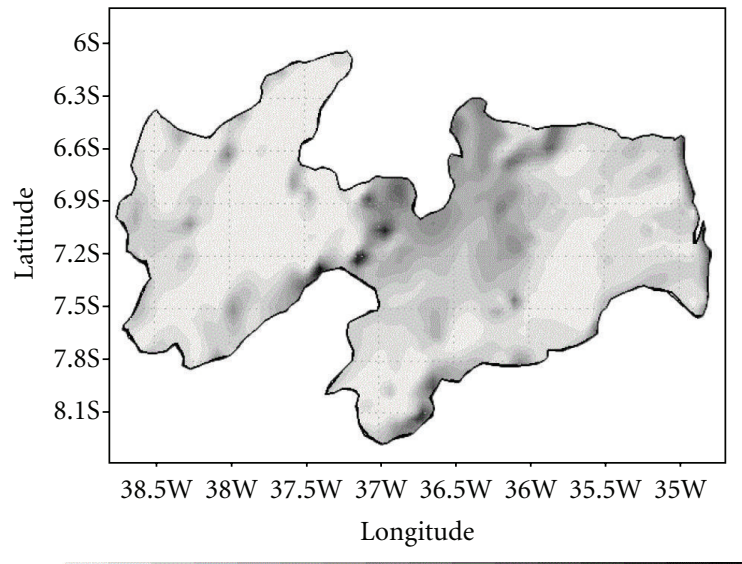

$20 \quad 3550 \quad 65 \quad 80 \quad 95110125145160175190205220235$

(b)

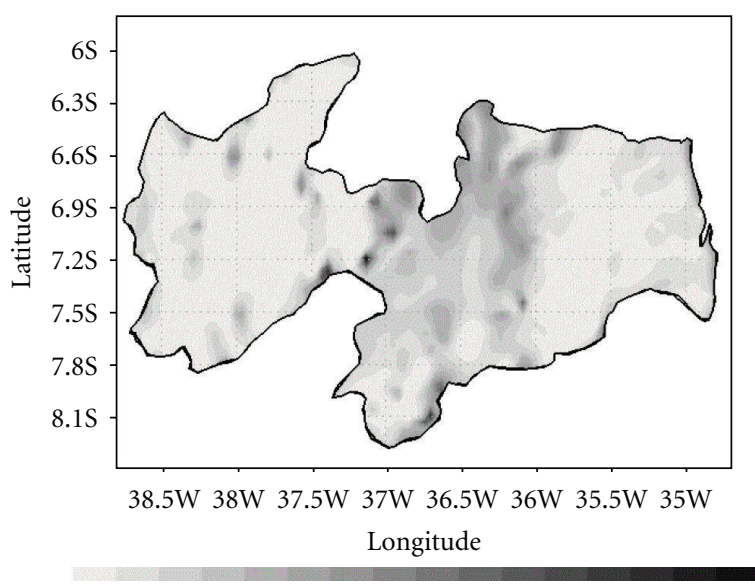

$15 \quad 3045 \quad 55 \quad 70 \quad 85100110125140155165180195210$

(d)

Figure 13: Mean wind power density in $\left(\mathrm{W} / \mathrm{m}^{2}\right)$ for the State of Paraíba for the following periods: (a) September 1977, (b) September 1981, (c) October 1977 and (d) October 1981.

Planalto da Borborema, where there are the Monteiro and Campina Grande stations. It is also possible to verify that for the month of March the higher values were in the year of 1977, while for the month of April the higher values were found in 1981.

In Figure 13 there is the configuration of the State of Paraíba for the density of wind power in $\mathrm{W} / \mathrm{m}^{2}$. As expected, the period considered dry obtained the best configuration for the wind power, in the region, in relation to the period considered rainy; that is, the results for the months of September and October were superior to the results observed in the months of March and April, as can be seen comparing Figure 12 to the Figure 13. The best sites for wind power density were again in Planalto da Borborema, as observed in the previous graphic, but with some focus in the shore of the State where there is the João Pessoa station, and in the Sertão region of the State of Paraíba, where there are the São Gonçalo and Patos stations.

\section{Conclusions}

It was concluded that the numerical simulations to estimate the wind speed at $10 \mathrm{~m}$ high distant from the soil showed, in general, a satisfactory performance with good relation between the series of simulated data, in comparison to the observational data. And, as seen in the statistical indexes with high correlation for the rainy period, that is, the model simulated well the period considered rainy in the region.

In all cases, the model had difficulty in reproducing the variation of a short-time scale. Thus, it can be concluded that the local factors are not well represented in the model, what could be corrected with the utilization of a microscale model. As well as the use of surface data from different sources from the ones used in this research, having better spatial resolutions and high quality.

In further works in this line of investigation, wind power provision, it is proposed the use of a model of microscale, 
as the WASP, in order to detect the phenomena that occur in short-time intervals, as well as the use of better surface data in the model BRAMS, to redo the simulations, amplifying the simulation period. Data of great scale of varying sources to initialize the model can also be used.

\section{Acknowledgments}

The authors thank the National Institute of Metheorology (INMET), for the data used in this research. Also thanks are due to the Coordenação de Aperfeiçoamento de Pessoal de Nível Superior (CAPES), for the financial support.

\section{References}

[1] C. G. Justus and A. Mikhail, "Height variation of wind speed and wind distribution," Geophysical Research Letters, vol. 3, pp. 261-264, 1976.

[2] L. van der Auwera, F. de Meyer, and L. M. Malet, "The use of the Weibull three-parameter model for estimating mean wind power densities," Journal of Applied Meteorology, vol. 19, no. 7, pp. 819-825, 1980.

[3] I. L. Sauer, M. S. Queiroz, J. C. G. Miragaya, R. C. Mascarenhas, and A. R. Q. JÚnior, "Energia Renováveis: ações e perspectivas na petrobras," Bahia Análise e Dados, vol. 16, no. 1, pp. 9-22, 2006.

[4] W. R. Cotton, R. A. Pielke, R. L. Walko et al., "RAMS 2001: current status and future directions," Meteorology and Atmospheric Physics, vol. 82, no. 1-4, pp. 5-29, 2003.

[5] H. M. H. Juang and M. Kanamitsu, "The NMC nested regional spectral model," Monthly Weather Review, vol. 122, no. 1, pp. 3-26, 1994.

[6] J. Duhdia, D. Gill, K. Manning, W. Wang, and C. Bruyere, PSU/NCAR Mesoscale Modeling System Tutorial Class Notes and Users'Guide (MM5 Modeling System Version 3), 2005.

[7] R. A. Pielke, W. R. Cotton, R. L. Walko et al., "A comprehensive meteorological modeling system-RAMS," Meteorology and Atmospheric Physics, vol. 49, no. 1-4, pp. 69-91, 1992.

[8] R. L. Walko, C. J. Tremback, and R. F. A. Hertenstein, The Regional Atmospheric Modeling System. Version 3b. User's Guide, ASTER Division, Fort Collins, Colo, USA, 1995.

[9] E. P. Cavalcanti, Teor e transporte de vapor d'água na atmosfera do nordeste do Brasil [Tese de Doutorado-UFPB], Campina Grande-Paraíba, Brazil, 2001.

[10] C. Chen and W. R. Cotton, "A one-dimensional simulation of the stratocumulus-capped mixed layer," Boundary-Layer Meteorology, vol. 25, no. 3, pp. 289-321, 1983.

[11] H. L. Kuo, "On formation and intensification of tropical cyclones through latent heat release by cumulus convection," Journal of the Atmospheric Sciences, vol. 22, no. 1, pp. 40-63, 1964.

[12] H. L. Kuo, "Further studies of the parameterization of the influence of cumulus convection on large-scale flow," Journal of Atmospheric Sciences, vol. 31, pp. 1232-1240, 1974.

[13] J. Molinari, "A general form of Kuo's cumulus parameterization," Monthly Weather Review, vol. 113, no. 8, pp. 1411-1416, 1985.

[14] J. Molinari and T. Corsetti, "Incorporation of cloud-scale and mesoscale downdrafts into a cumulus parameterization: results of one- and three-dimensional integrations," Monthly Weather Review, vol. 113, no. 4, pp. 484-501, 1985.
[15] G. A. Grell and D. Dévényi, "A generalized approach to parameterizing convection combining ensemble and data assimilation techniques," Geophysical Research Letters, vol. 29, no. 14, article 1693, 4 pages, 2002.

[16] E. P. Souza, Estudos teóricos e numéricos da relação entre convecção e superfície heterogêneas na região Amazônica. $121 \mathrm{f}$ [Tese Doutorado em Meteorologia], Universidade de São Paulo, 1999.

[17] G. L. Mellor and T. Yamada, "Development of a turbulence closure model for geophysical fluid problems," Reviews of Geophysics \& Space Physics, vol. 20, no. 4, pp. 851-875, 1982.

[18] E. D. de Freitas, L. D. Martins, P. L. da Silva Dias, and M. de Fátima Andrade, "A simple photochemical module implemented in RAMS for tropospheric ozone concentration forecast in the metropolitan area of São Paulo, Brazil: coupling and validation," Atmospheric Environment, vol. 39, no. 34, pp. 6352-6361, 2005.

[19] E. D. Freitas, C. M. Rozoff, W. R. Cotton, and P. L. Silva Dias, "Interactions of an urban heat island and sea-breeze circulations during winter over the metropolitan area of São Paulo, Brazil," Boundary-Layer Meteorology, vol. 122, no. 1, pp. 43-65, 2007.

[20] J. L. Devore, Probabilidade e Estatística Para Engenharia e Ciência, Thomson Pioneira, São Paulo, Brazil, 2006.

[21] R. A. Anthes, "Cumulus parameterization scheme utilizing a one-dimensional cloud model," Monthy Weather Review, vol. 105, no. 3, pp. 270-300, 1977.

[22] D. S. Reis Junior, "Previsão sazonal de vazões no estado do ceará," in Proceedings of the 8th Simpósio de Recursos Hidricos do Nordeste, Associação Brasileira de Recursos Hídricos, Gravatá-PE, Brazil, 2006.

[23] A. H. Weber, M. R. Buckner, and J. H. Weber, "Statistical performance of several mesoscale atmospheric dispersion models," Journal of Applied Meteorology, vol. 21, no. 11, pp. 1633-1644, 1982.

[24] P. H. S. Maria, Modelagem numérica em alta resolução para previsão de geração de energia eólica no ceará. 123 f [Dissertação de Mestrado], Fortaleza-Ceará, Brazil, 2007.

[25] E. B. A. C. Cunha, Investigação do potencial eólico de região serrana no ceará. Dissertação [Mestrado em Ciências Físicas Aplicadas], Universidade Estadual do Ceará, 2008.

[26] G. Huang and A. T. Paes, "Posso usar o teste t de Student quando preciso comparar três ou mais grupo?" Einstein, vol. 7, no. 2, pp. 63-64, 2009.

[27] H. E. A. Menezes, Influência da zona de convergência secundária do atlântico sul sobre a ocorrência de precipitação no leste do Nordeste Brasileiro [Tese de Doutorado-UFCG], Campina Grande-Paraíba, Brazil, 2010.

[28] A. L. Bruni, Estatística Aplicada à Gestão Empresarial, Atlas, São Paulo, Brazil, 2007. 

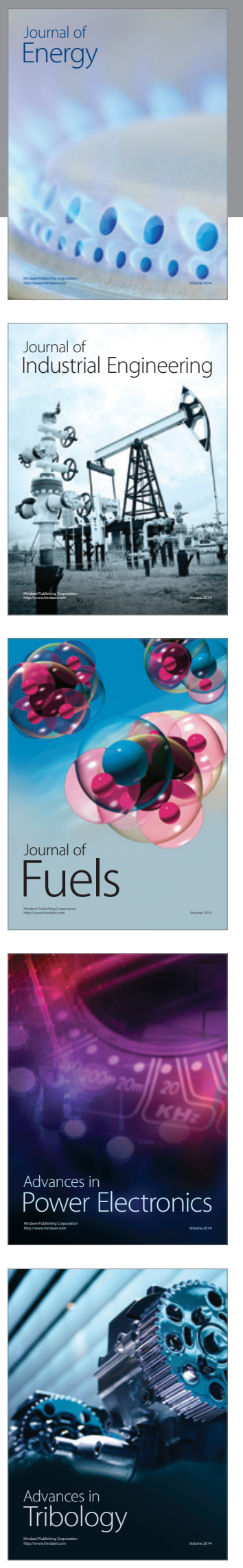
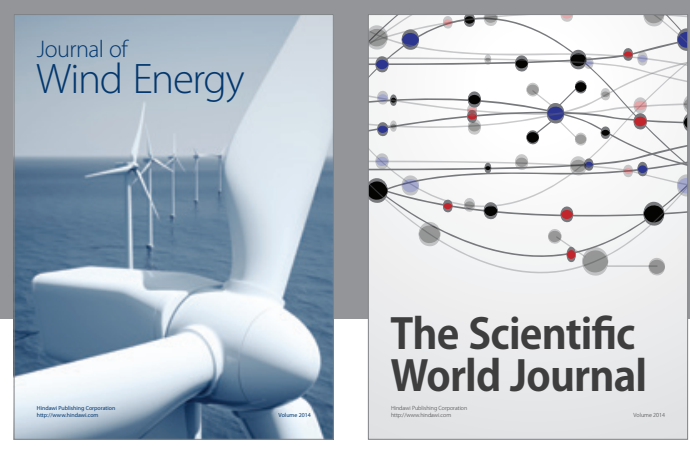

The Scientific World Journal

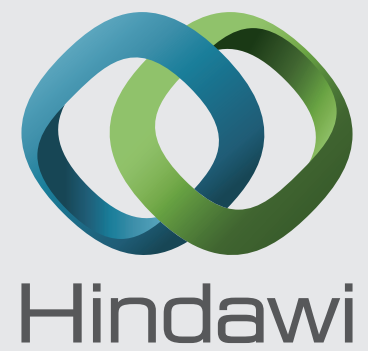

Submit your manuscripts at http://www.hindawi.com
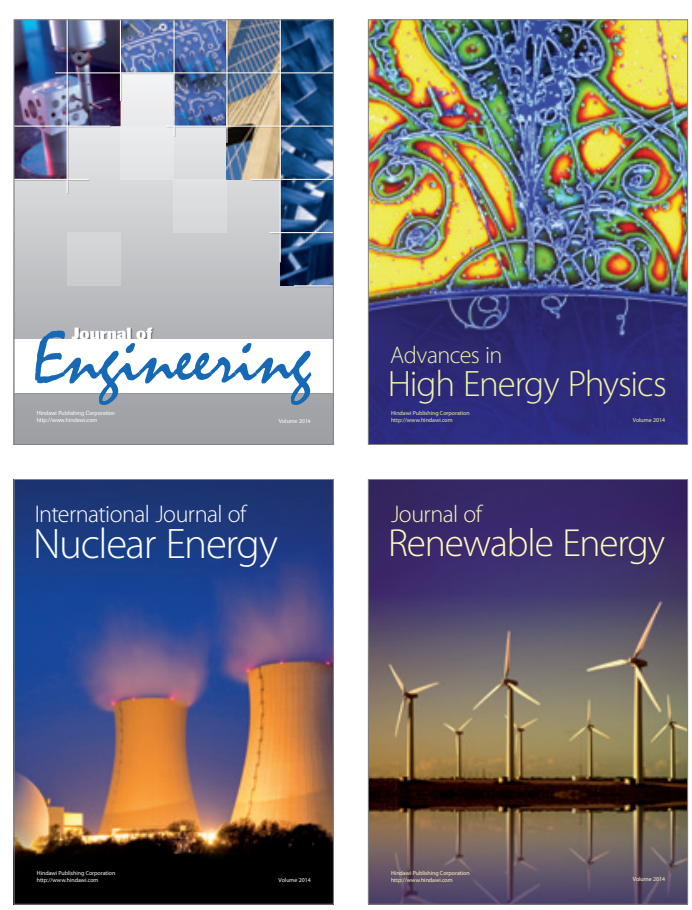

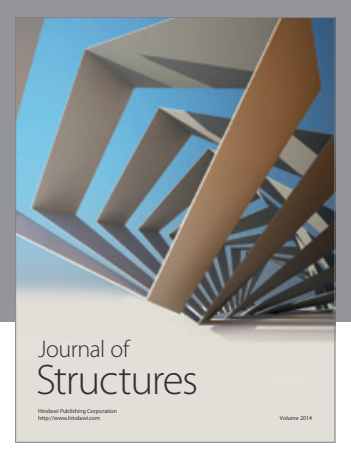

Rotating
Mechinery
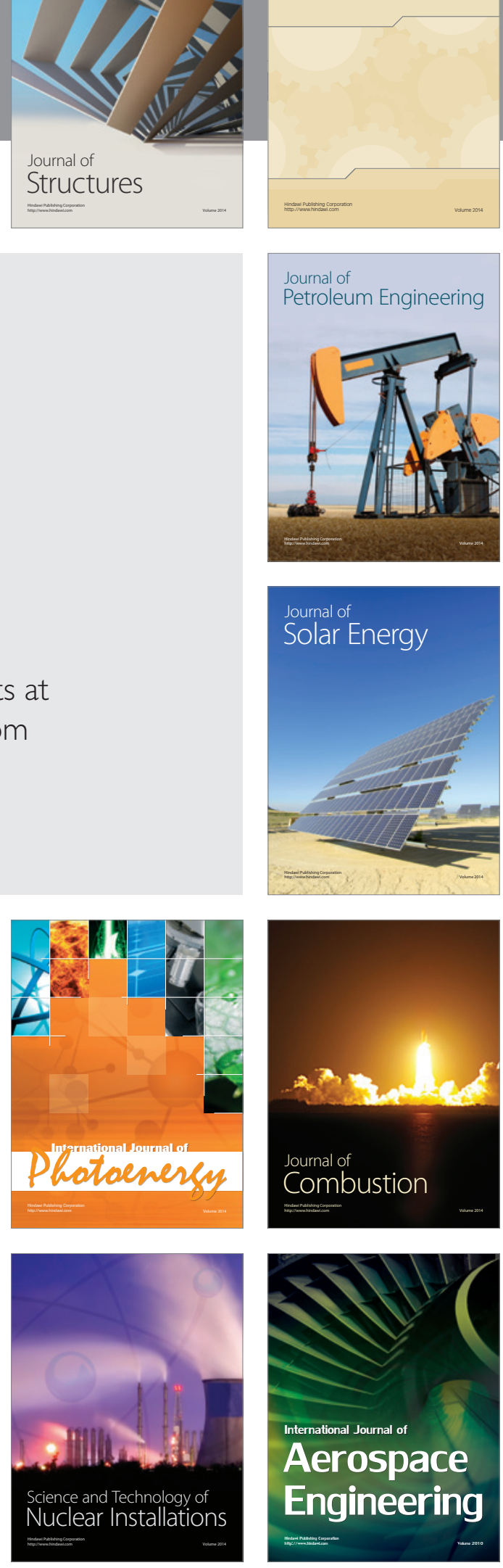